S H

396

$-1183$

\title{
A PRACTICAL METHOD OF SPONGE CULTURE
}

From BULLETIN OF THE BUREAU OF FISHERIES, Volume XXVIII, 1908

Proceedings of the Fourth International Fishery Congress : : Washington, Igos

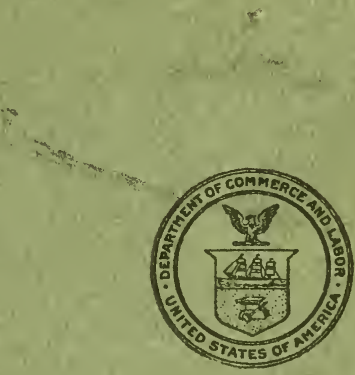

WASHINGTON : : $: \quad: \quad: \quad$ GOVERNMENT PRINTING OFFICE $: \quad: \quad: \quad: \quad: 1910$ 


$$
\text { \% }
$$








\section{A PRACTICAL METHOD OF SPONGE CULTURE}

From BULLETIN OF THE BUREAU OF FISHERIES, Volume XXVIII, r908

Proceedings of the Fourth International Fishery Congress : : Washington, roo8

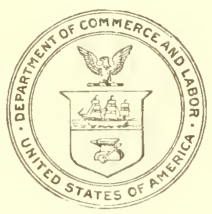

WASHINGTON : : : : : : GOVERNMENT PRINTING OFFICE $: \quad: \quad: \quad: \quad: \quad: 1910$ 


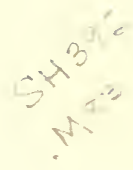

BUREAU OF FISHERIES DOCUMENT NO. 669

Issued March, 1910 


\title{
A PRACTICAL METHOD OF SPONGE CULTURE
}

\author{
$\infty$ \\ By H. F. Moore
}

Scientific Assistant, L'nited States Bureau of Fisheries

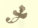

Paper presented before the Fourth International Fishery Congress held at Washington, U. S. A., September 22 to 26, 1908, and awarded the prize of $\$ 100$ in gold offered by Hayes Bigelow for the best demonstration, based on original investigations and experiments, of the commercial possibilities of growing sponges from eggs or cuttings
\end{abstract}




\section{CONTENTS.}

\section{*}

Page.

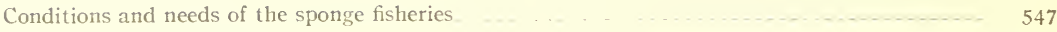

Previous experiments in sponge culture . . . . . . . 550

Possible lines of experiment:

Grafting _.............. 553

Growing from eggs _ . _ _ _................. 554

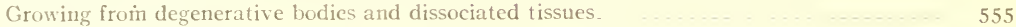

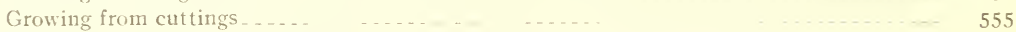

Propagation of sponges from cuttings:

Seed sponges. ...

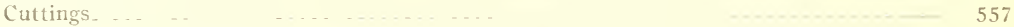

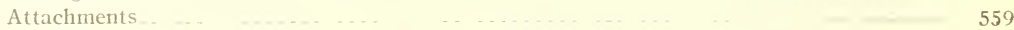

Planting .... _... _... _ _... 560

Rate of growth .... _... ......................... 569

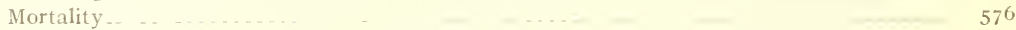

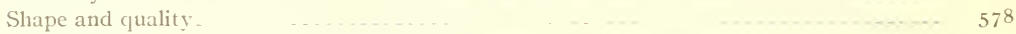

Harvesting ... . . . . . . . . . . . . . . . . 579

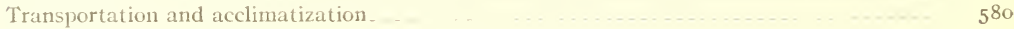

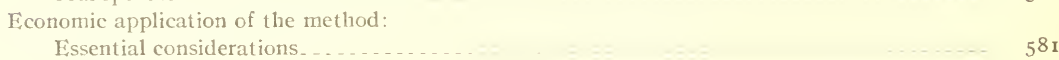

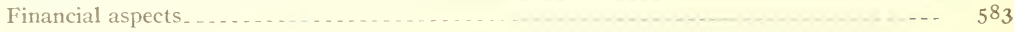



BUL. I. S. B. F., 1908.

PLATF IAVII.
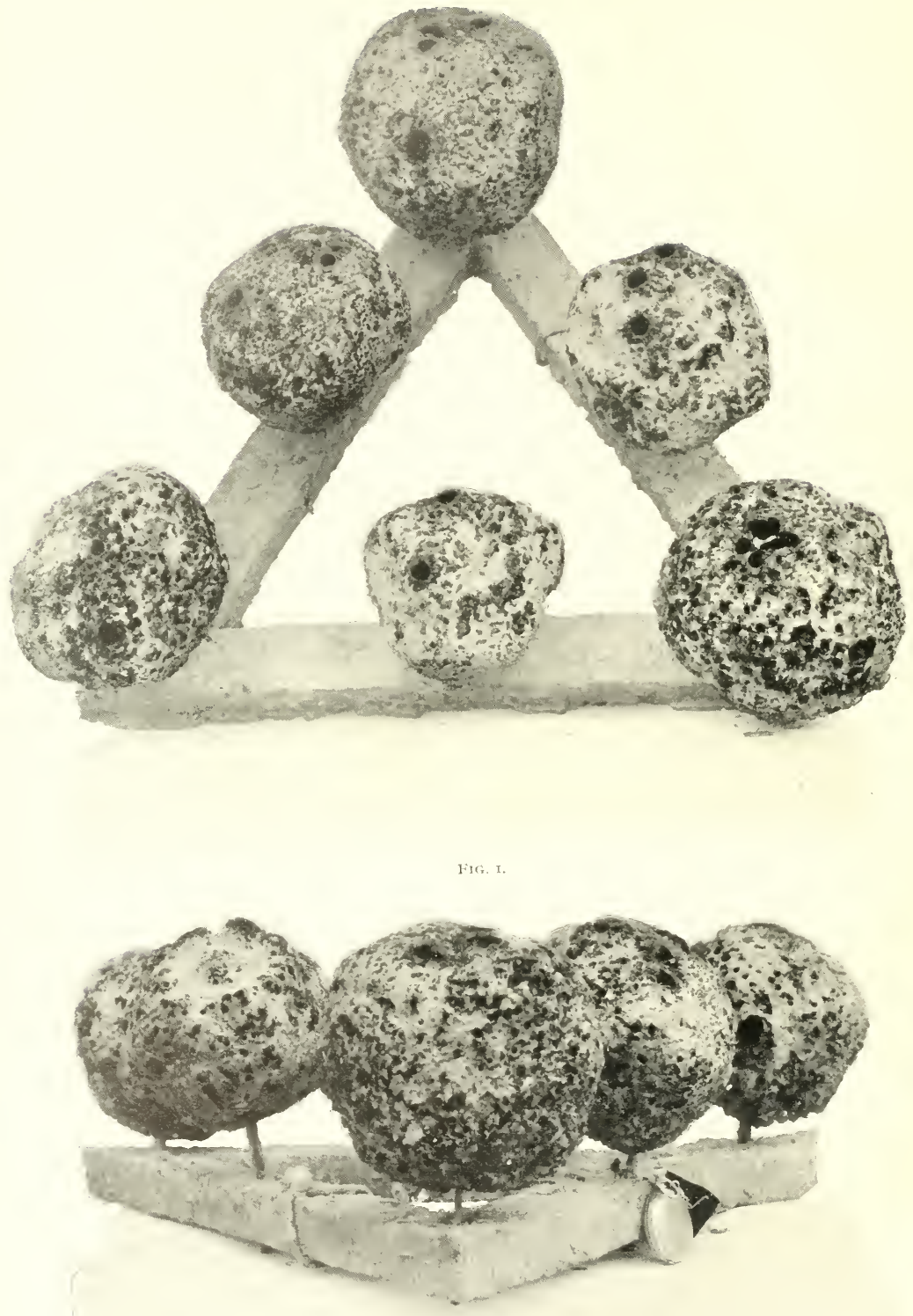


\title{
A PRACTICAL METHOD OF SPONGE CULTURE.
}

\author{
$*$ \\ By H. F. MOORE, \\ Scientific Assistant, United States Bureau of Fisheries.

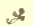 \\ CONDITIONS AND NEEDS OF THE SPONGE FISHIERIES.
}

As has been shown elsewhere, ${ }^{a}$ all or most of the important sponge beds of the world are being fished in such manner as to give more or less grave concern as to their depletion. In the Mediterranean, the Bahamas, Cuba, and Florida the danger of commercial extinction is exciting discussion among the thoughtful, though often denied by the more shortsighted of those who are most intimately concerned, the persons who as fishermen and dealers are dependent upon the sponge fishery for a livelihood. The reasons for the imminence of this danger the writer has elsewhere discussed and the condition is here taken for granted.

Statesmen, men of science, and men of affairs have all taken part in the discussion of the measures necessary to perpetuate the supply of this commercially valuable and almost essential product, viewing the situation not only from the standpoint of the sponge fisherman and the dealer, but from the more important view of the consumer, who can find no satisfactory substitute for the sponge in many of its applications to the arts and domestic uses. It is indubitable that the threatened extinction of many of the beds is due to the employment of methods of fishing which are in themselves destructive, and that, especially in Florida, the Bahamas, and Cuba, a still greater danger lies in the improper use of methods which, properly controlled, would be open to no reasonable objection.

The illegitimate taking of small sponges on the Florida coast by both divers and hookers is, for instance, an almost wanton destruction of natural wealth. Many of these small sponges, of little practical use and worth but a few cents apiece, if given two years' additional growth would increase in value a score, and in addition would furnish myriads of larval sponges to replenish the bottoms bared by more legitimate operations. Every young sponge has

$a$ Moore, H. F.: Commercial sponges and the sponge fisheries, Bulletin Bureau of Fisheries, vol. XXviIr, 1908, p. 399-5II. 
commercial potentiality both as an individual and as a parent, and in both respects its utility is vastly curtailed by premature destruction.

Legal neasures for the prohibition of especially destructive methods, and the regulation of abuses connected with the more legitimate means of taking sponges, would undoubtedly, if properly enforced, do much to make more remote the depletion of the beds. But aside from the difficulties encotintered in enforcing such legislation, as is witnessed in the failure of the considerable navies maintained by some of the states to enforce the oyster laws, such regulation could but retard the approach and not prevent the arrival of the day when the product of the natural beds will be inadequate to the demands of the markets. Even a legitimate fishery prosecuted under the spur of an increasing demand is eventually able to exterminate for all practical commercial purposes any sedentary organism toward which it may be directed.

When the demand is light and prices consequently low, as they were for many years after the discovery of the Florida beds, the more populous grounds only may be worked with profit. Then the sponges become so few and scattered that the time spent in looking for them greatly exceeds that expended in actually taking them from the bottom, profits are reduced to a degree when a closed season is automatically established by the removal of the spongers to other and denser grounds, and an opportunity is given for the replenishment of the beds by natural means. As the demand increases and the product becomes more valuable, more persons are attracted to the fishery, the methods become more efficient, and the degree of depletion of the beds, serving as a deterrent to further operations, more nearly approaches the limit of actual extinction. The beds are scoured year after year for the few remaining sponges, the decreasing supply and the increasing demand operating together to make profitable a closeness of search before unthought of and giving a value to sinall and otherwise undesirable sponges which in the earlier days of the fishery would have been allowed to lie ummolested on the bottom for want of a market. The consequence of this is that when a ground is finally even partially abandoned as a profitable fishery so few sponges are left, and these are so small in average size, that the reproductive capacity of the area is most seriously reduced and a long time must elapse before the bottom ean be reseeded by nature's unaided operations.

Some assistance could be rendered by the establishment of closed seasons, not so much those which prohibit fishing for a more or less restricted period each year, but such as would deny the right to fish on given depleted areas for terms of sufficient duration to permit the remaining young sponges to grow to reasonable marketable size and become of greater potential value in reseeding the area with a fresh crop of young. If such regulation could be rigorously and intelligently enforced, and if it were supplemented by measures preventing the taking 
of sponges of a less diameter than at least $4 \frac{1}{2}$ or preferably 5 inches, the danger of extinction of our American beds would be eliminated; but there are certain serious objections which may be urged against this solution of the difficulty, which at best can be but a partial solution. Aside from the difficulties and expense of enforcing such regulations and the hardship which they may at times work upon the spongers, the most serious objection is that they would from their very nature restrict the output of the fishery, or, at best, would not permit its development commensurately with the increasing demands of the markets. The writer has discussed the question at length in the paper above referred to, but for present purposes it appears to be advisable briefly to consider again the force of the last and major objection just mentioned, particularly with reference to the waters of the United States, although the application is general.

That the demand for sponges is growing rapidly can not admit of dispute. Prior to the discovery of the beds of Florida the imports of sponges into the United States were insignificant, and of course none was produced at home. There was practically no demand, except for domestic purposes. Thirty years later, in 1879 , the imports had increased to an average value of \$roo,ooo to $\$ 120,000$, while the average annual importation for the three years from 1905 to 1907 was valued at no less than $\$ 531,745$. The domestic production grew from nothing in 18,4 to $\$ 200,000$ in 1880 and an average of $\$ 658,403$ per year from 1906 to 1908 , most of which was consumed at home. In certain other countries also, notably Russia, Turkey, Spain, and the various states of South America, where very few or no sponges were formerly used, the past two decades hare developed an important consumption. With the development of civilization and modern methods of industry the countries of Asia, too, are sure to make important demands for this practically indispensable product of the seas.

No doubt new beds will be discovered from time to time and new regions will come into productiveness, but it is not believed possible, in view of what is known of the resources of the sea in most localities in which sponges may be expected to occur, that any vast areas producing the more desirable grades will be brought to light. If regulations governing the fisheries will merely preserve what we now have and will not materially augment production, there is forced upon us consideration of the necessity and possibility of increasing the supply by artificial means analogous to those employed in oyster culture or some other type of aquiculture. From a study of the breeding and life history of the commercial sponges two broad avenues of experiment open themselves. Research has shown that sponges may be propagated either in the natural sexual way by means of eggs, or artificially by cuttings or their equivalent. The following is a brief history of various observations, experiments, and suggestions in these directions: 
The basis of sponge culture by means of cuttings is in an observation made by $\mathrm{F}$. Cavolini ${ }^{a}$ in $\mathrm{I}_{7} 85$, that sponges cut into pieces would attach to foreign bodies and grow.

In 1862 Oscar Schmidt ${ }^{b}$ repeated and confirmed this observation and was apparently the first to make the practical suggestion that the regenerative phenomena might be utilized in the development of a system of sponge culture. This suggestion bore fruit in the following year when the Austrian Government and certain merchants of Trieste established a station on the island of Lesina, which in 1867 was placed in charge of Gregor Buccich. Of the experiences of the first four years of this work there appears to be no record, but Buccich submitted a report which was made the basis of a paper by Dr. Emil von Marenzeller $^{c}$ in 1878 .

Buccich appears to have discorered most of the salient facts relating to the growth of sponges from cuttings. He found that sponges can be removed from the water and cut in the air without injury; that in cool, damp weather they can be exposed to the air for eight hours without suffering material injury; that they can be cut and handled with less liability to injury during the winter; and that the cut surfaces will grow together or to certain foreign bodies with which they may be placed in contact. He observed also that apparently similar cuttings were sometimes dissimilar in their rates of growth, and that some cuttings would lieal and live for years without material increase in size. Concerning the rate of growth, the information is indefinite. The cuttings were small (about $I$ (?) inch cube) and they are stated to have doubled or trebled in size (bulk?) during the first year, and to have grown to a "considerable size" in five years, but that seven years would be required to produce a commercial product. There is no statement of the actual mortality among the cuttings experimented with, but it is estimated, upon what basis does not appear, that it would not be over ro per cent during the seven years.

The methods employed by Buccich were various. He pegged the cuttings to stones, to the inside of wooden boxes, and to various other contrivances. In perforating the cuttings to admit the pegs, which latterly were of bamboo, he used "a trepan 6 millimeters wide, fastened to a vertical turning table, which was kept in rapid motion by a fly wheel." The experiments were ultimately abandoned after nine years, mainly on account of the hostile attitude of the inhabitants. The somewhat elaborate methods of liandling and planting

a Cavolini, F.: Memorie per servire alla storia de' polipi marini. Naples, 1785 .

$b$ Schmidt, O.: Die Spongien des Adriatischen Meeres. Leipzig, 1862.

c Ton Marenzeller, E.: Die Aufzucht des Badeschwammes aus Theilstücken. Vienna, 1878. Translated in Report L. S. Fish Commission, 1879, p. $771-777$. 
the sponge and the character of the materials employed appear to have been unfit for commercial application. Marenzeller observes: "As far as our present knowledge goes, it is certain that sponge culture will not be profitable for poor men, but can be only carried on successfully on a very large scale either by wealthy individuals or by joint stock companies."

The failure of Buccich's work to yield commercial results appears to have ended experiments in Europe, but about 1879 Mr. Fogarty, a sponge buyer of Key West, Fla., planted 216 cuttings in a depth of about $2 \frac{1}{2}$ feet of water. The pieces were about $21 / 2$ inches long; they were attached to the bottom by sticks and wires, and it is stated that it required four months to repair the injuries and reestablish growth. Four specimens, said to be six months old, sent to the National Museum are stated to have grown from four to six times the bulk of the original cuttings. This experiment was never pushed to a conclusion, and the fate of the cuttings, other than those mentioned, is unknown. A few years later Mr. R. M. Munroe, of Cocoanut Grove, Fla., began work in Biscayne Bay, where for several years he experimented in fastening cuttings to stones and various arrangements of stakes forming hurdles and frames. A large proportion of the pieces survived and grew to some extent, but none reached a greater bulk than 3 or 4 cubic inches, and practically all were eventually destroyed or lost. The bottom selected and the materials employed were in some cases unsuitable and in others the antagonism of some of the spongers prompted them to destroy the plants. At this time the first spongeculture law was presented to the legislature of Florida, but it was subsequently so amended as to be highly objectionable and unjust to the spongers and it consequently failed of passage.

About r $897-98$ several thousand cuttings were planted at Sugar Loaf Key by Dr. J. V. Harris, of Key West. They were attached to galvanized iron wire laid on the bottom, but the wire soon corroded and broke into short pieces, the sponges became detached, and the mortality was very high. From time to time I have picked up a considerable quantity of this wire with a few attached sponges. Growth appears to have been slow or, after a while, almost entirely arrested, and the largest specimens seen by me have been under 4 inches in diameter at an age of from 3 to 5 years, the exact age of any given specimen being indeterminate. The quality of the sponges in the vicinity of their attachment was also injured by iron rust. In addition to the sponges planted as described, Doctor Harris planted many thousand cuttings by sowing them broadcast over the bottom. It is not improbable that some of these may have attached to rocky patches of bottom and grown, but if so they became indistinguishable from the natural growth, and their history is lost. 
In January, 1898, Dr. H. V. Wilson presented before the National Fisheries Congress, held at Tampa, Fla., a paper ${ }^{a}$ making some suggestions on rearing sponges from the egg and on improving their quality by grafting. In June, 1907, he published $^{b}$ some results of his experiments with certain noncommercial sponges at the United States Fisheries Laboratory, Beaufort, N. C., demonstrating that they could be raised by regeneration from degenerate masses to which the sponge is reduced under certain artificial conditions of confinement. Doctor Wilson suggested that this phenomenon would probably be presented by the sponges of commerce and might be utilized in a system of sponge culture for economic purposes. The same investigator has since discovered that practically the same effect can be produced by squeezing the soft parts of the sponge through bolting cloth into vessels of sea water, the expressed tissue substances, aggregating themselves into little heaps on the bottom, eventually regenerating the skeletal tissues and developing into complete sponges. None of these experiments has been performed on commercial species and the growth of the new individuals has not been kept long under observation, but I believe that there is no good reason to doubt that it would be possible to apply the methods successfully to any of the economic sponges of Florida.

With the exception of my own investigations and the related and parallel experiments of Messrs. Cheyney and Bigelow recounted in the main part of this paper, I believe the foregoing to cover all actual experiments in sponge culture, save one or two cases in which a very few cuttings or small sponges have been planted on the bottom by persons engaged in the industry; but in I895 Bidder ${ }^{c}$ considered the question from a purely academic standpoint and raised certain questions as to the utility of the whole project. Mr. Bidder on a priori grounds reached the provisional conclusions, inter alia (I) that the total volume of the new sponges grown from cuttings would not exceed the volume of the original sponge if it were permitted to attain its natural growth under the same conditions for an equal time; (2) that sponges or cuttings raised above the bottom, as in Buccich's experiments, would probably grow more rapidly than the same or similar individuals on the bottom; and (3) that the sponge-bearing area, naturally confined practically to the bottom, might be extended by using a suspension system of culture in which several strata between the surface and the bottom might be utilized by appropriately constructed supports for the growing sponges. How far some of these questions are answered by my own experience will be seen in the following pages.

$a$ Wilson, H. V.: On the feasibility of raising sponges from the egg. Bulletin U.S. Fish Commission, vol. XVII, 1897 , p. $241-245$. 1898 .

$b$ Wilson, H. V.: A new method by which sponges may be artificially reared. Science, n. s., vol. xxv, no. 649, p. $912-915.1907$.

$c$ Bidder, George: Notes on projects for the improvement of sponge fisheries. Journal of the Marine Biological Association of the United Kingdom, vol. Iv n. s.) p. $195-202$. 
POSSIBLE LINES OF EXPERIMENT.

Under instructions from the Commissioner of Fish and Fisheries, experiments in sponge culture were inaugurated in January, I90 I, at Sugar Loaf Key and at divers places in Biscayne Bay. From the beginning the aim las been not to demonstrate purely scientific possibilities, but to develop, if possible, a system of sponge culture having present economic application, the condition of the fishery being such that there may arise at any time an exigency demanding immediate measures of relief to the overtaxed natural beds.

As has been seen from the preceding historical résumé, a number of theoretical considerations have been offered by various persons and several attempts have been made toward a solution of the problem. It has been proposed to multiply and improve sponges by growing thein from cuttings, from the egg, and from the peculiar degenerative masses described by Wilson, and by grafting superior varieties upon those less desirable. Each of these, except the third, which has been but recently discovered, was considered when the present experiments were begun.

\section{GRAFTING.}

It does not appear that there is much of value in the suggestion as to grafting, which is based upon an imperfect analogy between certain aspects of the process of growth in sponges and in the higher plants. Cut surfaces of related varieties of sponges, as of related varieties of plants, will fuse and heal if brought into proper apposition, but there the analogy ends. In grafted plants each member of the union (stock and scion) furnishes essential parts of the compound, the stock supplying the roots and trunk of a tree, while the scion develops the branclies, foliage, and fruit. Without foliage the stock would die, and without roots the scion would not survive. In plants, too, each member of the graft produces a definite influence on the resultant whole, making it more or less unlike either of the pure varieties of which it is compounded. The fruit produced on the scion will differ from that which is produced by the ungrafted stock, while the influence of the latter may be seen in greater hardiness, a different size and general habit, or in other respects. With sponges the case is quite different. The two members of the union will have the same organs and be essentially similar even though they may differ in quality and texture. One piece may be attached or rooted, but that is immaterial and in a measure acciclental, for the so-called root is merely a part of the surface adherent to some foreign body and performs no particular function other than that of anchorage. If the sponge be torn loose, some other part of the surface may with equal facility become the root, or more likely the sponge will continue to live and grow as an unattached individual or "roller." As has been shown by experiment, if a graft be made, each piece will continue to grow independently without influence upon its fellow except in limiting 
the direction of its growth, although the character of one or both may be affected by any change in environment. A cutting from a sponge transplanted and grafted on another growing in a different environment will tend to approach the latter in character, not as the result of the graft, but on account of the physical surroundings, precisely as it will do if transplanted to the same locality without grafting. In other words, nothing can be done by grafting that can not be more readily done by propagation from cuttings which attach themselves, and the former process results in a waste of time and effort without compensating advantages. Neither cutting is improved by the amalgamation. Sponges of the same species will unite if grafted. Sheepswool sponges from different localities readily fuse, but they will not unite to either yellow or grass sponges, and probably not to any species other than their own.

\section{GROWING FROM EGGS.}

That sponges can be grown from eggs to a marketable size under the control which is essential to any system of sponge culture appears probable, but it has not yet been demonstrated. Although experiments made with the noncommercial sponges show that they can be kept alive for a considerable time after development from the egg, I know of no cases in which they have been artificially raised to maturity or to any considerable size, and experiments with the commercial sponges are still less conclusive. Raising sponges from the egg must probably always remain a delicate operation, practicable only to skilled investigators provided with special facilities and entirely beyond the reach of the practical man engaged in a commercial enterprise. For that reason the method appeared to be ill-adapted to the present needs of the sponge fishery and was therefore discarded in the experimental work described in the present paper. As has been pointed out, however, in an academic discussion of the proposition by H. V. Wilson, it may be that this method will have a distinct place in the sponge culture of the future, though its development and practice must probably necessarily be in the hands of a few skilled operators. It may be possible to breed sponges from selected parents, thus improving their quality and supplying better seed sponges from which to make cuttings. Possibly some system of hybridization may be developed along lines analogous to those which have produced such astounding results in the hands of experimental horticulturists.

The plasticity of sponges and their extreme susceptibility to environmental influence, as well as the technical difficulties which the experimenter must overcome in his attempts at breeding and hybridization, will probably long postpone, if they do not entirely defeat, successful efforts in this direction. The problem is one which may well be taken up and studied when the Bureau of Fisheries comes into possession of a properly equipped laboratory in the sponge region of Florida. 
GROWING FROM DEGENERATIVE BODIES AND TEASED OR DISSOCIATED TISSUES.

Wilson's extremely interesting and scientifically important studies in this field open, as he points out, a new means by which sponges may be propagated. The experiments so far have been confined to noncommercial species, but there appears to be no reason for believing that they can not be applied to horny sponges. In fact, in certain "sick" sheepswool sponges in my experimental plants I have observed in the dead skeletal remains certain degenerative masses resembling, at least superficially, those described by Wilson in silicious sponges.

Wilson's methods are to induce the partial death of the sponge and the production of small degenerate bodies in the remaining living tissue, or to tease up the soft tissue, or finely divide it by squeezing it through bolting cloth bags. The resulting small masses speedily attach and regenerate into little sponges.

Leaving out of consideration the morphological significance of these processes, and viewing them solely from the practical standpoint of sponge culture, these methods of rearing sponges appear to be essentially similar to rearing from cuttings made with a knife, the main difference being that the tissue aggregates, or pieces, are obtained by an elaborate method instead of a simple one.

GROWING FROM CUTTINGS.

This metlod was adopted as that giving greatest promise of success, and it is discussed in detail in the following chapters.

\section{PROPAGATION OF SPONGES FROM CUTTINGS.}

Growing sponges from cuttings has to recommend it, as a practical method, its simplicity and the certainty with which the excised pieces will attach and regenerate when placed under suitable conditions. The ease with which suitable seed sponges may be obtained at any season, their immunity from the effects of more or less rough handling, the facility and rapidity with which they can be attached to such materials as may be selected, the promptness with which they will grow fast to suitable foreign bodies, and the certainty with which they heal and grow into perfect sponges make this an immediately feasible method of sponge culture, provided the proper means of attachment and methods of handling can be developed. How far the present experiments have solved the problems will be seen in the following account.

\section{SEED SPONGES.}

For seed any healthy sponge may be used, whatever its shape or size. Torn and irregular specimens, or those so filled with sand and other foreign matter as to make them of little value in the markets, may be utilized equally with wellshaped ones, though they often do not cut so economically in respect to either material or time. When the seed sponge is heavily loaded with shells, corals, 
and similar material, there is always considerable waste and much time is lost through the dulling of knives and the necessity of avoiding obstacles too stout to cut. For this reason it is economy to select the cleaner specimens for seed when they can be readily obtained. The sponges as fast as detached from the bottom should be placed in a gunny sack or net attached to the side of the boat or, if taken by diving, carried by the diver, the sack when full being emptied into a live ear. During cool or moderately warm weather, treated thus, they will remain alive and uninjured for several weeks, though if the sea be rough their surfaces are likely to become more or less abraded by rubbing against the sides of the ear. They must not be brought into water at all brackish, lowever, or they will be speedily killed. In warm weather if long confined even in salt water some will sicken and die, and the resulting foul water will soon produce a general epidemic.

In carring live sponges from the beds to the planting grounds a boatshaped or spindle-shaped live car will be found most convenient, as either can be towed rapidly and for long distances without injuring the contents. The car should be provided with several "thwart-ship" bulkheads or partitions dividing it into compartments, and the slits or perforations in the forward end should be small or narrow so as to reduce the violence of the currents set up by its rapid passage through the watcr. If these openings be large, the sponges will churn violently or be massed under pressure at the after ends of the compartments and are certain to be more or less injured. The car prefurably should be constructed entirely of wooden slats and boards, as wire netting tends to abrade and injure the surfaces of the sponges. Where a boat with a small "well" is available, sponges can be transported in that, or when the distance is short they may be carried in tubs of water protected from the sun by eloths or sacks, but they should be remored from the tubs and placed in open water as soon as opportunity oceurs. In cool weather they can be readily carried for many hours without water if they are protected from the sun and rain and kept moist with sea water. At the planting grounds the sponges may be kept best and most conveniently by stringing them on rope yarns about 5 or 6 feet long, the two ends of which are then tied to stout lines or wires stretched between stakes so that the sponges are suspended just clear of the bottom. In a situation where the water is sufficiently salt and pure they will readily live longer than the lines will last, and at the same time they will be easily accessible, those required from time to time being conveniently detached without disturbing the remainder.

There is some reason to believe, as is discussed later, that in regions which have been for years subject to an intense fishery, especially where the water is shallow and generally clear, a race of slow-growing small sponges may be developed by constantly selecting out the larger more rapidly growing specimens, 
and that cuttings made from such seed will not grow as rapidly as those from more virile stock. When there is reason to suspect this, seed should be brought from other localities.

\section{CUTTINGS.}

In the beginning of the present experiments the cuttings used were small, about I by $\mathrm{I}$ by $\mathrm{I} / 2$ inches, the purpose being to secure as many plants as possible from a given quantity of seed sponges. This size gives from 100 to I 20 plants from a 6-inch sponge. Theoretically the use of small cuttings was correct for securing the greatest ultimate product from a given amount of material. As is shown hereafter, the average growth in diameter is fairly constant for the first four years at least, and the relative increase in volume or weight is therefore greatest when the cuttings are small. Growing at the average rate of $I$ inch per year, I 20 cuttings made from a 6-inch sponge would in four years reach a volume of about 75 times that of the original sponge, provided there was no mortality, whereas the same sponge cut into 20 pieces, in the same time and under the same conditions, would increase about 20 times, while if the seed sponge were planted entire it would increase but 4 or 5 times, provided it grew at the average rate established for specimens up to 8 inches in diameter. This is illustrated in principle, though not in detail, in figure 6, page 575. The solid line shows graphically the growth of an entire sponge, the middle dotted line the aggregate increase in a sponge of the same size cut into 20 pieces and the upper line the increase when cut into 50 pieces, in eách of the latter two allowance being made for a mortality of 5 per cent of the cuttings per annum.

It was found, however, that the smaller pieces were placed at considerable disadvantage by reason of the greater readjustments required to perfect again the canal system, and moreover when they were injured, as frequently happens, a proportionately larger part of their substance was affected and the regeneration required to convert the fragments into functionally and anatomically perfect sponges was more drastic. These two factors operated to produce a somewhat higher mortality in the small cuttings than in larger ones, and moreover tended to retard materially the growth of the first six months, though after that there was little difference between the diametric increase of large and small pieces. The smaller cuttings also require a longer time to reach a marketable size, the planter has to wait longer for his returns, and in the meantime the sponges are subject to such risk of disaster as may exist. In properly selected localities the last consideration is not very grave. It was necessary, therefore, to effect a compromise between the theoretically economic advantage of employing small cuttings and the practical biological superiority of large ones, and it was finally established that pieces about $1 \frac{1}{2}$ by $2 \frac{1}{2}$ by 3 inches 
(pl. Lxix) or of approximately the same volume, were the best, all things considered. The shape of the cuttings will, of course, vary with the size and shape of the seed sponge, but the more nearly equilateral they can be made, the more generally satisfactory they will prove. Thin edges or ragged parts are likely to die and slough off.

In making the cuttings it is generally better first to cut away the roots of the seed sponges if they contain fragments of rock or coral or shells. Otherwise much time is lost through the dulling of the knives. For this rough work it is well to use a heavy knife with its edge serrated by vertically grooving the flat face of the blade with a three-cornered file, converting it into practically a sharp-edged saw. For making the actual cuttings large butcher knives of good quality should be employed, and they should be kept sliarp by frequent whetting with a coarse stone, such as is used for sharpening scythes. A rather rough ragged edge is preferable to a smooth one. If the knife be in proper condition the sponges will cut as readily as beef liver, but if it be dull the operation is slower and the cuttings are liable to injury by the compression of their tissues under the knife.

The direction of the cuts will depend upon the size and sliape of the seed sponge, but in the majority of cases the latter should be placed on a wet board, root down, and cut into slices from $1^{1}+$ to $\mathrm{I}^{3}{ }^{3}$ inches thick, each of these being subdivided to best advantage as dictated by the judgment of the operator. It is desirable, but not essential, to leave on eacli cutting one surface covered by the uninjured skin of the original sponge. I lave successfully grown cuttings taken from the interior of the sponge, but while the mortality is no ligher and a new skin is soon formed over the entire surface, growth appears to be somewhat more slowly initiated than in the case of normal cuttings.

Neither the seed sponge nor the cuttings are injured by moderate exposure to the air, but it is safer, especially in hot weather, to throw the pieces into a tub of fresh sea water as soon as cut. Care should be exercised to change the water at intervals of about one hour, as the cuttings will be injured and probably die if left for any length of time in foul water and a few fragments of dead sponge will speedily contaminate a tulbful. Neither the entire sponge nor the cuttings should ever be brought into water much below oceanic saltness and care slould always be taken to protect the tubs from rainfall, which appears to have an effect disastrously out of proportion to its volume. If it is necessary to keep cuttings over night they should be placed in netting bags and hung in the open water, but they should never be so left more than a day or two, as they will soon grow together and be separable without injury only by the knife. Specimens left in contact for three or four days have grown into conglomerate masses difficult to handle. 
ATTACHMENTS.

The chief problem confronting the experimenter in sponge culture is to find some ready and economical means of attaching the cuttings to a durable support which shall be capable of resisting the chemical action of sea water and the ravages of the teredo and other animals having similar destructive habits, and which at the same time is without injurious effect upon the sponges. During the course of the present experiments numerous materials and methods were employed, most of which sooner or later demonstrated their unfitness to fill the requirements. It was found that the cuttings would speedily attach to any firm, clean, innocuous material, and many methods of attachment appeared satisfactory for a year or two, but then developed some defect due to corrosion, tensile weakness, or the lack of sufficient attaching surface. It was necessary to await developments before the direction of further experiments was indicated, and much time was expended on materials which afterwards developed unexpected defects.

During the first season the cuttings were attached to stakes and rectangular frames laid on the bottom, to rertical stakes, and to pieces of coral rock and small copper wires laid on the bottom. Some of the sponges were threaded on the supporting copper wires and others were bound to them by means of short pieces of lighter wire, with the expectation that the sponge would eventually encompass its support. About six weeks after the plants were made it was found that 95 per cent had healed and were living under apparently healthy conditions, but seven or eight months later most of them had died. It was expected that the action of the sea water on the copper wires would produce poisonous salts, but in quantities so small as to have merely a local effect. It was found, however, that wires one-sixteenth inch in diameter were completely corroded away in places, especially where the cuttings were attached, and the latter were either killed, or lost by the breaking of the wires. The effects were especially pronounced when the wires were lying on the bottom. The cuttings placed on the bottom on rocks and stakes soon became covered with silt and vegetable growths and were either killed or lost, and it was evident that the choice of both materials and localities had been unfortunate.

During the winter of $190 \bar{x}-2$ advantage was taken of the experience gained during the preceding year, and in addition to Biscayne Bay and Sugar Loaf Key, where the first year's experiments were made, Anclote Key was selected as an additional locality. Instead of using naked copper wires, various types of insulation were tried, other metals, including lead and heavily galvanized iron, and various cordage materials were experimented with, and molded forms of terra cotta, plaster, and cement were used in place of the rocks and stakes placed on the bottom. The more or less expensive insulations composed of 
various patented compounds of rubber, etc., which have been found to possess superior properties for electrical purposes, soon developed their worthlessness for sponge culture, the insulation being affected by salt water and stripping from the wires. Underwriters' insulation, so called, a cheap covering of cotton and white lead, proved to be more durable and lasted for upward of two years, but it, too, eventually stripped or crumbled from the wire. Ordinary telegraph wire electrolytically galvanized rusts very quickly and breaks into pieces. Iron wire galvanized by the "hot process" will last for a number of years if kept fully immersed in sea water, but when it is periodically partly exposed at low water it rusts more quickly, and moreover the zinc coating kills that part of the cuttings brought into contact with it. Iron wire coated with lead is also quickly destroyed, and copper wire coated in the same way kills the sponges. Plain or "black" iron rusts quickly and breaks, and the iron salts are injurious to the fiber of the sponges. Aluminum wire is innocuous as to its salts in sea water, but is rather expensive when of sufficient diameter, and is subject to rapid corrosion in spots, causing it to break into pieces.

Asbestos cord was found to be practically indestructible chenically, but when wet the fihers become loose and frayed and so slippery that the tensile strength is seriously reduced. This difficulty was overcome by treating the cord with rubber solutions, white lead, a mixture of paraffin and asphaltum and other waterproofing and cementing substances. This treatment very greatly increases the strengtl of the cord, especially in the water, but the rubber is somewhat expensive and the asphaltum, clespite its mixture with paraffin, has an abrasive effect on the cuttings and wears large holes where the cord passes through the growing sponge.

Jute, sisal, manila, cotton, and hemp lines were employed, but as expected, they were all quickly destroyed in salt water. Coir (cocoanut fiber) rope was not experimented with, as there was some difficulty in obtaining it, and moreover, experiments with the fiber showed that it, too, is more or less quickly rotted in the water.

Stakes and other wooden structures placed on the bottom are quickly riddled by the teredo and other boring organisms. If planted green with the bark on they will last longer, but the bark of the most durable, the mangrove, has a bad effect on the sponges, while that of other trees tends to scale off after a while, the sponges becoming detached with it. If there were no better method available, black mangrove and white wood stakes stripped of bark would probably hold together for four years, but to prevent rotation and capsizing they must be nailed together in frames.

To none of these materials, excepting the barked stakes, did the cuttings make organic attachment. When the artificial attachments loosened, the cuttings were free to rotate and drift on the wire, and when the latter was at 
all rough, holes of considerable size were eroded in the sponge. Asbestos cord treated with rubber solution was least objectionable in this respect, owing to the softness of its surface and the firmness with which it could be gripped by the binding wires, the method of applying which is explained later.

It was found that this difficulty of the corroding wires was obviated by the use of lead wire, to which the cuttings speedily form organic attachment and cling independently of artificial aid. The tensile strength of this metal is so low, however, that in spans it will not support itself, to say nothing of the weight of the sponges and the pressures exerted by waves and currents. To secure the virtues of lead, its freedom from corrosion, its chemically inert and innocuous qualities, and the facility with which the cuttings grow fast to it, while at the same time eliminating its defect of tensile weakness, the device was adopted of employing a strong fiber or wire core encased in a thin coating of lead.

Several types of this construction have been employed with varying success. One of the earliest was ordinary tarred marline encased in lead about one thirtysecond inch thick. This was light and when new quite strong enough for the purpose, but eventually the marline rotted and the lines broke, though some lasted for two years. Asbestos cord covered in the same way was also experimented with and found unsatisfactory.

Several forms of lead-covered insulated wires have been used, but the ordinary commercial sorts have been unsatisfactory, being either too heavy and expensive, or, if sufficiently light and cheap, lacking in durability. Commercial underwriters' wire witl a copper core and specially encased in lead was superior to the higher priced insulations, and a still better wire was of the same type with the copper core replaced by galvanized iron. This had to be made to order, as there are no such insulated iron wires on the market.

All of these wires and lines were used in the same general way, stakes being driven in the bottom in parallel rows at intervals of about 25 feet and the wires suspended between to form squares. At first the wires were attached merely by tying or winding them about the stakes, but it was found that this rigid attachment caused them to break under the repeated flexure to which they were subjected by swaying in the waves. Later galvanized rings were placed over the stakes, four wires radiating at right angles from each toward the adjacent stakes, the whole being supported at a proper height above the bottom by means of a short wire attached to the stake and ring, respectively.

When lead-covered lines began to be employed they could not be attached directly to the rings on account of electrolysis, which would cause the iron to rust, and the rings were then wrapped with insulating tape to keep the two metals from coming in contact. Here another difficulty was encountered, the lead coating wearing through when loosely attached to the ring, or breaking near B. B. F. $1908-36$ 
the ring under repeated flexure when rigidly attached. In the latter case the insulation was abraded by the rubbing of the rough edges of the broken lead casing, and the exposed core broke by the concentration of flexure at the weakened point, or else, coming into contact with the lead, was destroyed by electrolysis.

To overcome this, horseshoe-shaped porcelain pieces were interposed between the rings and the wires, as shown in figures $I$ and 2. By this means the electrically antagonistic metals were kept apart and at the same time there
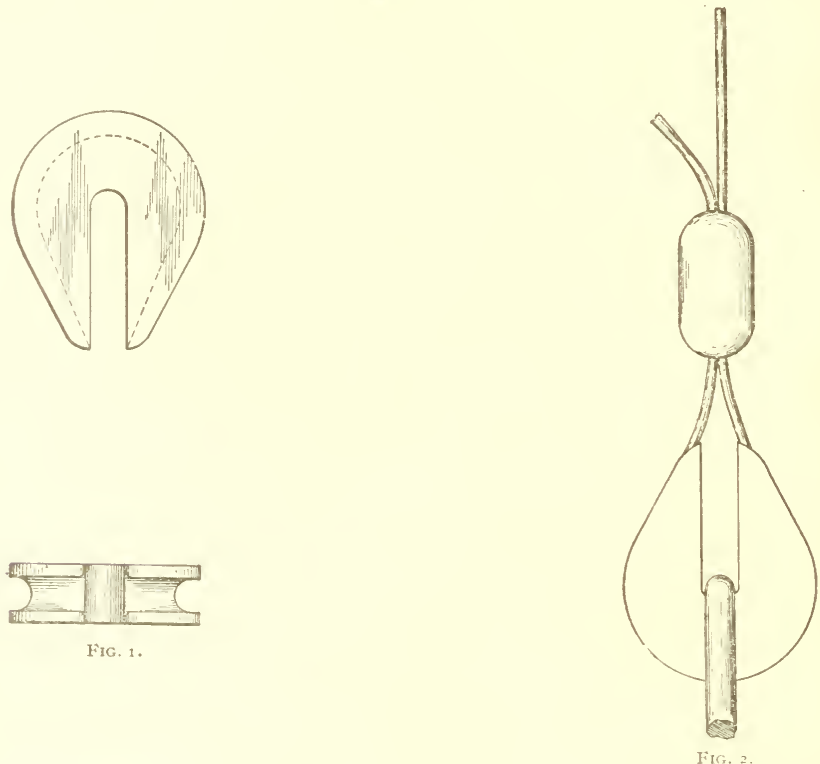

Fig. 1.

Fits. 2

FiIf. I AV1 2, - Showing insulated attachment for lead-eovered lines supporting sponge cuttings.

was formed a rocking attachment without wear on the lead, the flexure of the wire being distributect throughout its length instead of being concentrated near the stakes.

With galvanized iron wire with underwriters' insulation and incased in lead, this device served very well so long as the sponges were not much over 4 inches in diameter, but when they grew larger there was a contingency which had not been anticipated, the sponges being torn loose and rotating on the wire. Practically all of the wires 11 sed were less than one-fourth inch in diameter, a larger size being objectionable on account of its weight and the hole produced in the 
sponge. This gave a small surface of attachment which, while sufficient at first, became proportionally smaller as the sponge grew. The attached area, and consequently the strength of the attachment, grew proportionately to the diameter of the sponge, while the forces acting to loosen it grew in proportion to the surface exposed to the impact of the waves. The consequence was that in rough water sponges 5 inches in diameter were generally torn loose, and, once started to rotate or oscillate, a large hole was soon worn about the wire to the detriment of the quality of the sponge and the retardation of its growth. In sheltered places sponges were successfully grown on wires until they reached a diameter of 7 inches, but eventually they also must have become loose.

To correct this tendency to loosen, the shape of the wire was modified to assist the strength of the attachment by mechanical resistance to the rotation of the sponge, longitudinal slipping on the wire being negligible after the attachment of the cutting is once established. A galvanized iron ribbon three-eighths inch wide and one-sixteenth inch thick was incased in a tight-fitting lead jacket one thirty-second inch thick, the whole making a flat band one-eighth inch thick and not quite one-half inch in breadth. This appears satisfactorily to prevent rotation in sponges as large as 8 inclies in cliameter.

This lead-incased ribbon is durable so long as the casing is not mechanically broken or punctured. At the cut ends the iron rusts away slowly, but the contact between the iron and the lead is so intimate that the water at a depth of Io or $\mathrm{I} 2$ feet penetrates but an inch or two at most, and electrolysis is, therefore, strictly localized to the open ends. It has to be handled with care, however, as the thin lead is easily punctured and the slightest hole becomes the seat of electrolytic action to the speedy destruction of the iron and the consequent breakage of the ribbon. When carefully put out this material has lasted for three years with no other sign of impairment than the rusting away of about one-half inch of the iron where exposed at the ends. Its strength is great, as was demonstrated at Biscayne Bay during the great hurricane of 1906 when a piece of wreckage fouled some of it, pulling up deeply embedded stakes and flattening a $1 / 4$-inch wrought-iron ring without injuring the ribbon. It is heavy and difficult to handle when planting from a small boat and there is also some difficulty in attaching it at the stakes. It, of course, can be bent in but one plane, and it can not be attached clirectly to the rings owing both to the electrolytic effect upon the latter and to the abrasion of the lead casing of the ribbon.

In the experimental work porcelain insulators were attached to the rings by means of galvanized wire, the ribbon being bent over them, with a piece of thin sheet lead interposed, and secured by means of a flattened seine lead or piece of lead piping as shown in figure 2. In a commercial application a special insulator similar in general shape to that shown in figure $\mathrm{I}$ could be employed. In any case it is necessary to place a piece of sheet lead or asbestos 
cloth between the porcelain and the ribbon to prevent wear and tear on the lead covering of the latter.

All of the foregoing experiments were made with a view to the utilization of soft muddy or grassy bottom upon which sponges will not grow naturally and in depths not exceeding ro or $\mathrm{I} 2$ feet. This would have made possible the utilization of considerable areas among the keys and close to shore along the Gulf coast, in localities where the plantations could be readily protected. The results of the work, however, have failed to disclose a material which is satisfactory in all respects. The lead-covered iron ribbon if carefully handled and planted with its casing uninjured has sufficient durability and prevents the loosening of the sponges as they reach commercial size, but it is not a commercial product and has to be made to order, which militates against its use by small planters, while its weight makes it somewhat difficult to handle in lengths of more than 15 feet, this, in its turn, increasing the cost of stakes, rings, and attachments. The rings and insulators will last indefinitely, the stakes will have to be renewed once during the growth of the sponges, and the indications are that the ribbon, or at least most of it, will not be useful for a second planting. Lead-incased galvanized-iron underwriters' wire about onefourth inch in external diameter with no. 12 Brown \& Sharp gauge core is durable, costs about one-half as much as the ribbon, is easily handled, and much of it can be used for a second planting, but on account of its circular cross section the sponges as they grow will loosen and rotate in any but the most slieltered places.

The value of a method which would permit of the utilization of otherwise useless and barren bottom in shoal water is great and warrants further experiment, but the results so far obtained are not such as would justify the recommendation of any of the methods or materials experimented with. The experimental results of the work with wires are valuable on account of the facility with which the sponges could be examined and the data which it has been possible to obtain as to the rate of growth, the mortality, and the general behavior of the cuttings.

As has been inentioned, in the very beginning of the work experiments were macle with various bottom attachments. The use of stakes or poles has already been discussed and the objections stated. They never offered much encouragement for further trial. The plaster, cement, and pottery forms first employed were about 5 inches in diameter on the bottom, + inches on top, and about $\mathrm{I}^{\mathrm{I}} / 2$ inches thick. The larger face was slightly convex, and the smaller, to which the cutting was attached by neans of a $V$-shaped wire running through a central hole, was flat. They were found to be too small, tending to capsize as the sponges grew and offering greater surface to the impact of waves and currents, and there was also some difficulty with silt and vegetable growths which 
interfered with the welfare of the cuttings so that they were also difficult to keep under observation for experimental purposes.

Owing to the encouraging early results and the apparent advantages of the wire suspension methods previously described, provided a suitable material could be obtained, work with bottom planting was suspended for several years but was taken up again in 1905 when it became apparent that none of the lines and wires previously experimented with was likely to prove satisfactory. About the same time a sudden disaster, due to the presence of drainage water near the surface on the plantation at Anclote key, made it necessary to transplant hurriedly the remaining sponges to the bottom in another locality. Not only the plantation of the Bureau of Fisheries was affected, but also that of Messrs. Cheyney and Bigelow, who on an adjoining site had been, for two years preceding, conducting a similar experiment on a commercial scale.

Bricks, rocks, and anything available were first used in the hurry to remove the sponges from untoward influences, but in the meantime there were being made a number of cement disks larger and heavier than those used during the first two years of the experiment. These disks (pl. Lxvin) are about 10 inches in diameter and $I_{1} / 4$ inches thick, and are composed of a mixture of $\mathrm{I}$ part cement to 3 or 4 parts sand. They are molded in iron rings of the required dimensions laid on the sand, and two holes about + inches apart are made in each by thrusting through the cement before it hardens an iron bar three-eighths inch in diameter. The molds are removed as soon as the cement has set and before it hardens, the operation being facilitated by running a thin-bladed knife around the inside of the rings to break their adhesion to the disk. The disks can be made by this methor! for less than 2 cents each, including material and labor.

For experimental work hollow triangles (pl. LxviI) were sulstituted for the disks, six sponges being planted on each. As each triangle was marked or numbered, record could be kept of the gromth and behavior of the cuttings, and as the large triangles were less easily overlooked than the smaller disks and as each was planted with a definite uniform number of cuttings, the rate of mortality could be readily determined from time to time.

These disks and triangles are satisfactory on rocky bottom, but tend to bury on sand, marl, or soft mud. They may, however, be used on bottom with a sparse growth of grass. When the grass is long and dense it tends to fall over the sponges, causing death or irregular growth. Where shifting sands and silt are carried by the currents these materials tend to deposit in the eddies on the lee side of the disks and triangles, and eventually pile up around the base of the sponges and kill them. To obviate this difficulty spindles were placed in some of the triangles (pl. LXVII) and disks, six in each of the former and one in the latter, the cuttings being attached near their tops so as to prevent free flow of the currents beneath. These spindles project about 8 inches and various materials were tried, 
the most satisfactory being short lengths of the lead-covered iron ribbon before described. They serve the purpose perfectly, they are sufficiently durable, the sponges soon permanently attach, and no suffocation occurs in places where cuttings on the disks would be buried in mud or sand. The spindles are, however, about double the cost of the disks, and although the indications are that if carefully handled they will last long enough to mature two crops of sponges, they eventually will be destroyed while the disks are practically indestructible. The spindles also prevent close packing of the disks and are more troublesome to handle, but on the other hand they facilitate the attachment of the cutting, as will be lereafter explained.

\section{PLANTING.}

The method of applying the cutting to the support has undergone gradual modification. In the early experiments with various insulated wires, when the sponge did not form organic attachment, the pieces were bound against the supporting line with short pieces of aluminum wire thrust through the sponge and twisted around the support. It was found that the cuttings were often slow in growing around the support and should the binding wires become loose were likely to be detached and lost. To obviate this difficulty the expedient was adopted of slitting the cutting, placing the two legs of the slit astride of the supporting wire and bincling the sereral faces in close apposition by means of rubber bands or short aluminum wires traversing the two flaps of the cutting and at their cnds twisted around the supporting wire. Under such conditions the slit speedily fused and the cutting became organically intact about the wire. Aluminum was employed for binding because its salts in sea water are neither rapidly produced nor injurious.

With the use of lead-covered materials, to which the sponges grow fast, it became possible to "thread" the cuttings on the wire, the use of binding wires being unnecessary to hold them in position. To facilitate this operation needles (text fig. 3) were made of clock-spring steel, one end being shaped to a sharp stiletto point, and the other rolled or folded over to form a socket fitting the end of the wire on which the sponges were to be planted. In planting, the needle was fitted to the wire and the cutting pierced by the sharp end of the needle and pushed onto the wire as one would use an ordinary needle and thread in stringing beads. After attaching the ends of the wires to the stakes the cuttings were distributed at regular intervals by sliding them along with the hand, their friction against the lead usually holding them in place until organic attachment occurred. Several mechanical distributers were devised and experimented with, but none was very satisfactory.

In planting on plain disks the cuttings are pierced by short aluminum wires, the ends of which are carried through the two holes already described and twisted 
BuL. U. S. B. F., Igos.

PLATE LAVIII.

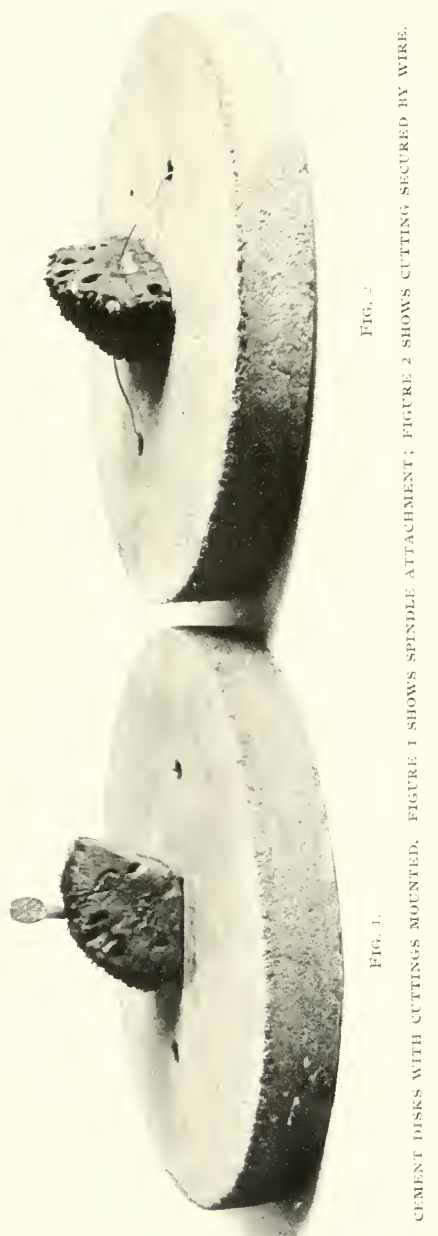



on the under side (pl. LxviI, fig. 2). This is a rather slow process, and it is not possible for two men to cut, attach, and plant more than about roo cuttings per hour. To accelerate the speed of planting I have placed in the center of each disk a short spindle of $1 / 4$-inch lead wire, slightly flattened at the top by a blow from a hammer and projecting to a length of about $2 \frac{\mathrm{T}}{2}$ inches (pl. LXVIII, fig. I). About 8 or Io cuttings are placed on a long needle (fig. 3 ) of the required shape, the socket of which is placed upon spindle after spindle in succession and the cuttings pushed into place in contact with the cement base, each with a single motion of the left hand. Friction of the slightly stretched tissues against the spindle and the burr at the top of the latter prevent the detachment of the cutting, which in a few days grows fast to both the spindle and the disk. With this device two men can plant from $25^{\circ}$ to 300 cuttings per hour, and this gain in speed over the other method is highly important in places where rough weather is prevalent, as it makes possible the fullest utilization of such opportunities as present themselves. The spindles add about 25 per cent to the cost of the plain disks, but as they will survive a number of plantings this cost is compensated for by the decreased cost of labor.

This system also facilitates replanting with cuttings at the time of harvesting of the first crop, as the grown sponges can be quickly detached and new cuttings substituted. In shoal water where the sponges can be taken with hooks, two additional men in the boat should be ample to detach the sponges and replant the disks as rapidly as they are brought
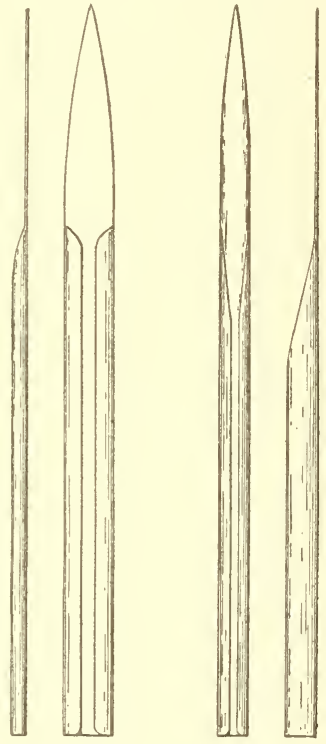
up. In deep water where a diver has to be employed for harvesting the crop, the cuttings can be taken down by the diver and planted as the matured sponges are removed, avoiding the labor and incon-

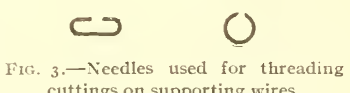
cuttings on supporting wires. venience of bringing the disks to the surface, and reducing the cost of operation very much more than sufficient to cover the increased first cost of the disks.

The expense of labor in deep-water planting is of such importance that the strictest economy of operation, especially in taking up the sponges, must be given careful consideration. The diver's time must be economized, as the time of the entire crew of the diving boat is dependent upon the rapidity and 
efficiency with which he works. The attachment of sponges to the disks by means of wires is slow under the best conditions and must be much slower under water where work is done at a clisadvantage, but the cuttings can be slipped on to the spindles as readily under water as in the air.

The same considerations apply to cuttings planted on long spindles (pl. Lxvir) which will hold them above the bottom and in deep water. Especially in a locality requiring the transport of the disks or triangles for considerable distances, the second planting can be carried on more economically than the first. Holes should be punched in the disks, however, even when spindles are used, so that a wire attachment can be employed should the spindle eventually be broken off.

The density with which sponges can be planted on the bottom in any given locality is a subject which will require actual experiment on a commercial scale for its elucidation. That ordinary waters will support a dense growth of miscellaneous sponges is well known, and among the Florida keys I liave observed an average of several to a square yard over considerable areas.

Though nothing is known of the actual facts concerning the food of sponges, it can hardly be doubted that all horny sponges feed on essentially similar material. If this be true, it is fair to assume that an area which will support a large number of useless horny sponges slould support and produce an equal volume of the commercial kinds. Unfortumately the shoal-water beds of our coast are now so depleted that present day observations are useless and the distribution of the valuable kinds on the deep water grounds is so unequal, owing to the irregular and sporadie occurrence of stitable bottom, that nothing definite can be learned. I am informed by Dr. H. M. Sinith, however, that in very shoal waters in the Philippine Islands he has seen commercial sponges somewhat similar to the Florida grass sponge averaging one to every square foot of the bottom over areas many acres in extent. The commercial experiment carried on at Anclote Key by Messrs. Cheyney and Bigelow showed that, even in an unfortunately selected locality, cuttings would grow rapidly when planted with a density of about one per square yard over an area of about is acres, and that the growth was no less satisfactory than upon the government's neighboring plantation covering but a few acres. In no case, on any of the plantations under observation, did the density of planting, up to a maximum of a little over one sponge per square yard, have any apparent effect upon the rate of growth. In bottom planting on a small scale sponges have been planted in some cases as densely as 5 or 6 per square yard without apparent bad effect, but with extensive areas so thickly planted it is possible that there might be an insufficiency of food. Experiments in Biscayne Bay appear to indicate that sponges grow more rapidly in strong currents, and presumably the same condition would permit denser planting than where the currents are weak. 
RATE OF GROWTH.

(Plates LXIX to Lxxvi.)

The rate of growth of cuttings is a matter of paramount practical importance to the prospective sponge culturist, and it has been the subject of considerable discussion and difference of opinion. The fishermen variously claim that on the natural beds sponges grow to a "marketable size," presumably 6 or 7 inches in diameter, in from six months to a year, basing their statements on the fact that grounds supposedly denuded one year are found to bear salable sponges the next. They fail to consider the certainty that they have overlooked a number of large specimens and numerous small ones already well on their way to merchantable size. Smith, in his paper, "The Florida Commercial Sponges," basing his statement upon the reports of others, says that the claims of the spongers are borne out by experiments, and that "in as short a time as one year, under favorable conditions, the cuttings will attain a marketable size, and certainly within sixteen or eighteen months the harvesting of relatively large sponges may be depended on." To substantiate the statement he furnishes a plotograph, a careful inspection of which creates the impression that the photographer has somewhat assisted nature in establishing the apparent rate of growth. I have reason to believe that both Dr. Harris, the grower of the sponges in question, and Dr. Smith were deceived as to both the age and the origin of the larger specimen, and that it came from a mangrove root and not from a wire, as supposed. As photographed it is about $5 \frac{1}{2}$ inches in diameter and is said to be not over eight months old, but I have seen a number of other sponges planted at the same time and place and under the same conditions which had attained a size of not over 4 inches when between three and five years old. They were all planted under unfavorable conditions, and the best result that I have been able to attain in the same locality and under better conditions of growth was an equal diameter in about two years from cuttings between 2 and $2 \frac{1}{2}$ inches cube.

The experiments by Fogarty at Key West about i 880 have not been accurately or definitely reported, but it is said that cuttings about $2, \frac{1}{2}$ inches in diameter in some cases increased from four to six times in bulk within a period of six months. This is more in accord with my own experience, though, as will be shown later, the relative increase in volume is greater with small cuttings than with larger ones.

The results obtained by Buccich are also out of accord with the popular view of the rate of growth of sponges under natural conditions, although the reports of his work are lacking in definiteness. His cuttings, about I inch cube, increased to two or three times their original bulk in one year and did not reach full marketable size, the exact dimensions not being stated, until the lapse of seven years, a much slower rate of growth than in Florida. 
My own experiments show that the raw surfaces of cuttings become pigmented within a few days and that at the end of a month they have completely healed and have begun to grow and project little papillæ or cones. Sharp angles and edges generally die and slough off slightly, and the central portions of the plane faces become swollen so that at the end of three months in small cuttings and somewhat later in larger ones there is evident a distinct tendency to rotundity. At the end of six months in many specimens the cut faces can not be distinguished from the original surface of the sponge and in practically none can they be determined except by the shape. In all cases there is a constant tendency toward a spheroidal or ellipsoidal shape, cubical cuttings approaching the former and irregular ones the latter form if suspended above the bottom, but all becoming cake-shaped if grown from basal attachments. (Compare plates Lxxiv and Lxxv.)

Growth takes place in all directions with approximate equality when the cuttings are suspended freely in the water, but is generally more rapid in the horizontal plane when the sponge is attached to a basal support. If the cutting be attached to a small horizontal surface it will grow downward over the edges, and if the surface be uneven it will project itself into all the irregularities and loles. For this reason, if basal attachments are used, it is desirable to have them with smooth surfaces and of a horizontal expanse greater than that of the sponges which it is desired to grow, otherwise considerable weight, and also time, is lost in trimming the marketable specimens to a desirable and uniform shape.

Buccich observed considerable variation in the rate of growth and my own experiments confirm his statements. Cuttings which, so far as could be determined, were similar in size, shape, and character, diverged widely from one another in this respect and some of them, wliile healing completely and remaining in an apparently healthy state, had grown hardly at all in the course of several years. In some cases cuttings made from the same sponge exhibited this diversity. Different lots of cuttings of the same average size and planted in the same locality exhibited a remarkably uniform average rate of growth year after year. In Sugar Loaf Sound the average annual increase in diameter was about 0.8 inch, while at Anclote Keys and Cape Florida it was from I to I.2 inclies. In Sugar Loaf Sound this arerage was maintained to the end of three years, when the experiment was abandoned for reasons already explained, while at the other two places it continued until the end of four years, when accurate records were lost as the result of disasters due to meteorological causes.

Recent developments in Biscayne Bay indicate that the average growth of sponges planted on the bottom in Cape Florida Channel is slightly in excess of the rate stated above, while at Soldier Key, about 7 miles away, it is much less. At the first locality the currents are strong, the bottom muddy, and the neighboring 


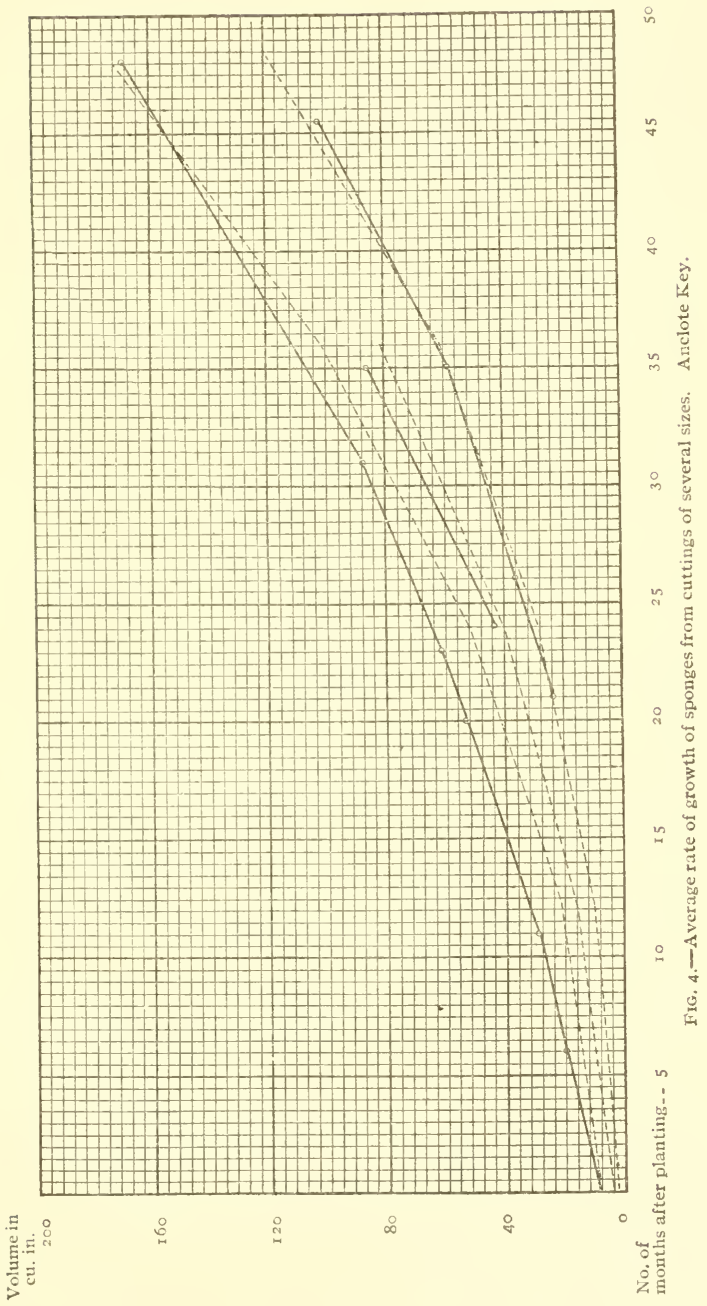




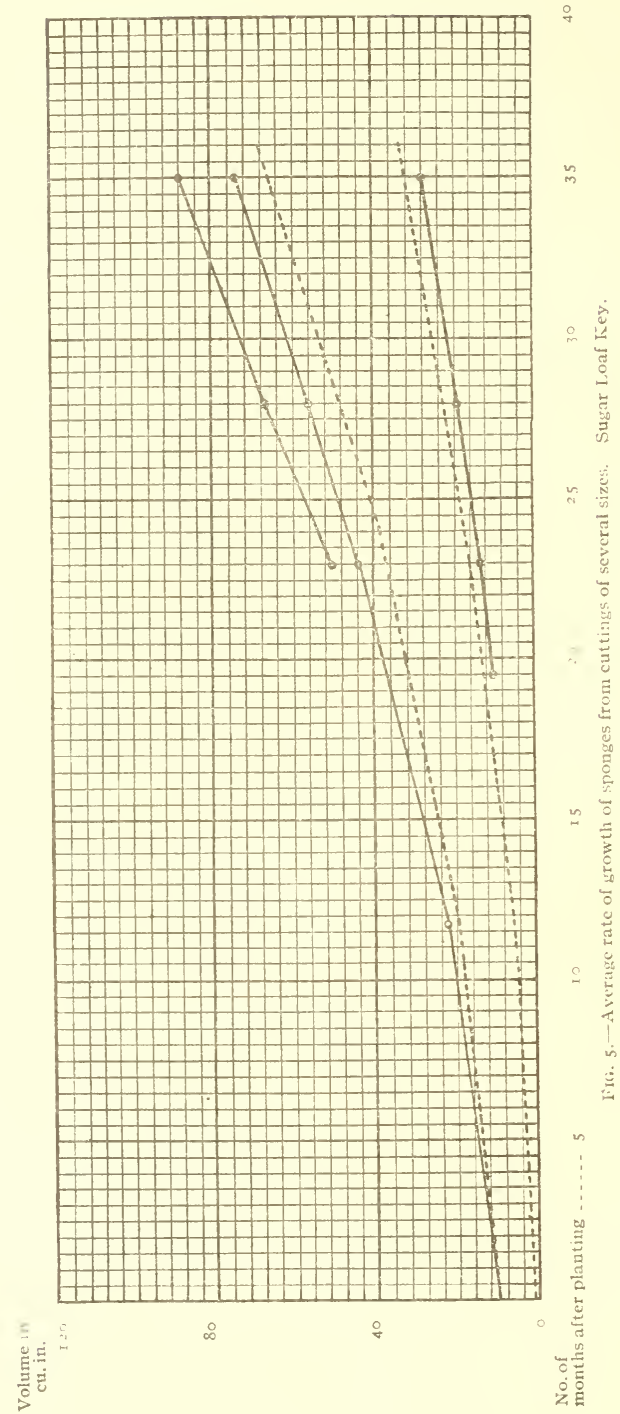


banks covered with vegetation, while at Soldier Key the bottom consists of clean rock, the adjoining banks are sandy, and the current is probably less rapid, though of the latter I am not certain. The difference in the rate of growth may be due to the strength of the current or to the larger amount of food in the waters adjacent to marine vegetation. That the latter is the probable reason is indicated by recent observations that sponges planted on bottom covered by short grass at Soldier Key exhibit a more rapid rate of growth than those planted on bare rock.

The slower rate of growth in the warmer waters of Sugar Loaf Sound was a surprise, and it may possibly be accounted for by the general absence of strong currents or by the character of the seed sponges. These were all small specimens rarely over 5 inches in diameter, obtained from the waters of the sound, which while formerly producing large ones now rarely do, possibly as a resuit of overfishing in former years. In these shallow waters the spongers have been able rigidly to select out all marketable sponges, a process which would logically tend to eliminate those which grew rapidly and had an inherited tendency to reach larger dimensions, while leaving a preponderance of those of slower or stunted growth to perpetuate their kind. The inevitable tendency of an intensive fishery of this character would be to breed a race of more or less dwarfed sponges of slow growth, an assumption which is in a measure confirmed by the fact that Sugar Loaf Sound formerly produced a much greater proportion of large sponges than it does at present. This could not be due to the intensity of the fishery during the period within which I have been familiar with it, as the sound was then closed to promiscuous fishing and the sponges had ample opportunity to grow to larger size than the average attained.

In Biscayne Bay and at Anclote Key the seed sponges were obtained from partially depleted beds, but owing to tile greater depth and the more frequent prevalence of turbid water these have never been so thorouglily scoured of marketable sponges. The specimens from which cuttings were made were larger, and presumably more virile, and in any event the cuttings grew more rapidly. At Sugar Loaf and Anclote Keys the planted sponges were measured at intervals after the first year by means of calipers, and occasionally specimens of average size were taken and cleaned. In Biscayne Bay local conditions prevented the systematic measurement of the sponges while growing.

Text figures 4 and 5 exhibit graphically the rates of growth in volume of the cuttings at Anclote Key and Sugar Loaf Sound, respectively. The dotted lines indicate the theoretical increase in volume, assuming a uniform annual increase in diameter of 0.8 inch at Sugar Loaf and I inch at Anclote Key, while the heavy lines show the average growth of a number of measured specimens of the ages indicated by the position of the small circles. It will be observed that the 
growth is fairly uniform up to the end of the fourth year, when there is a tendency to drop, but whether or not this late decrease in the rate is normal can not be stated, as the specimens measured had been injured by an influx of fresh water on the plantation.

The experiments with wires appeared to show that sponges suspended above the bottom grow more rapidly than those on or near the bottom, but more recent results with disks and triangles appear to throw some doubt on this. It is probable that dense vegetation among which the sponges lay had an inimical effect and that sponges planted on bottom where they would not be covered by vegetation would grow as rapidly, or nearly so, as those suspended above it. With bottom planting it is difficult to make accurate and systematic observations on a large scale, but such observations as have been made at Biscayne Bay and Anclote indicate that the rate of growth of cuttings planted on disks and spindles is at least equal to that of sponges planted on wires.

The question has been raised in regard to sponge culture whether if a sponge be cut into pieces the total growth of the pieces will be greater than the increase of the same sponge would have been if it had remained intact, the environment being identical in the two cases. It has been argued with some plausibility that the reply to this question is in the negative, but experiments at Sugar Loaf Key do not bear out this assumption, and it was determined that entire sponges from $2 \mathrm{I} / 2$ to $4 \mathrm{~T} / 2$ inches in diameter grow at approximately the same rate as healed cuttings of the same volume each. They both increased in diameter at the average rate of about 0.8 inch per year, some individuals in each exceeding and some falling short of the average. The greater aggregate increase in volume, therefore, is obtained by cutting the sponges into pieces, and the smaller the cuttings, provided the minimum leretofore stated is not passed, the greater the advantage of subdivision. This is expressed graphically in figure 6 , where the solid line represents the growth of an entire sponge 6 inches in diameter, and the broken line the aggregate growth of a sponge of the same diameter cut into 20 and 50 pieces, respectively, making an allowance of 5 per cent per year for mortality. The same data are shown in the following table.

Comparative Increase in Volume of an Entire Sponge and the Aggregate of Cuttings FROM SPONGES OF EQLAL Volume.

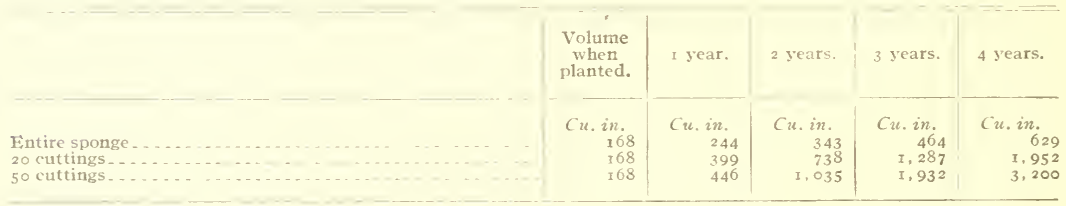


It will be seen that at the end of four years the volume of 20 cuttings made from a 6-inch sponge will be over three times that which the same sponge entire would have attained under the same conditions, while $5^{\circ}$ cuttings made

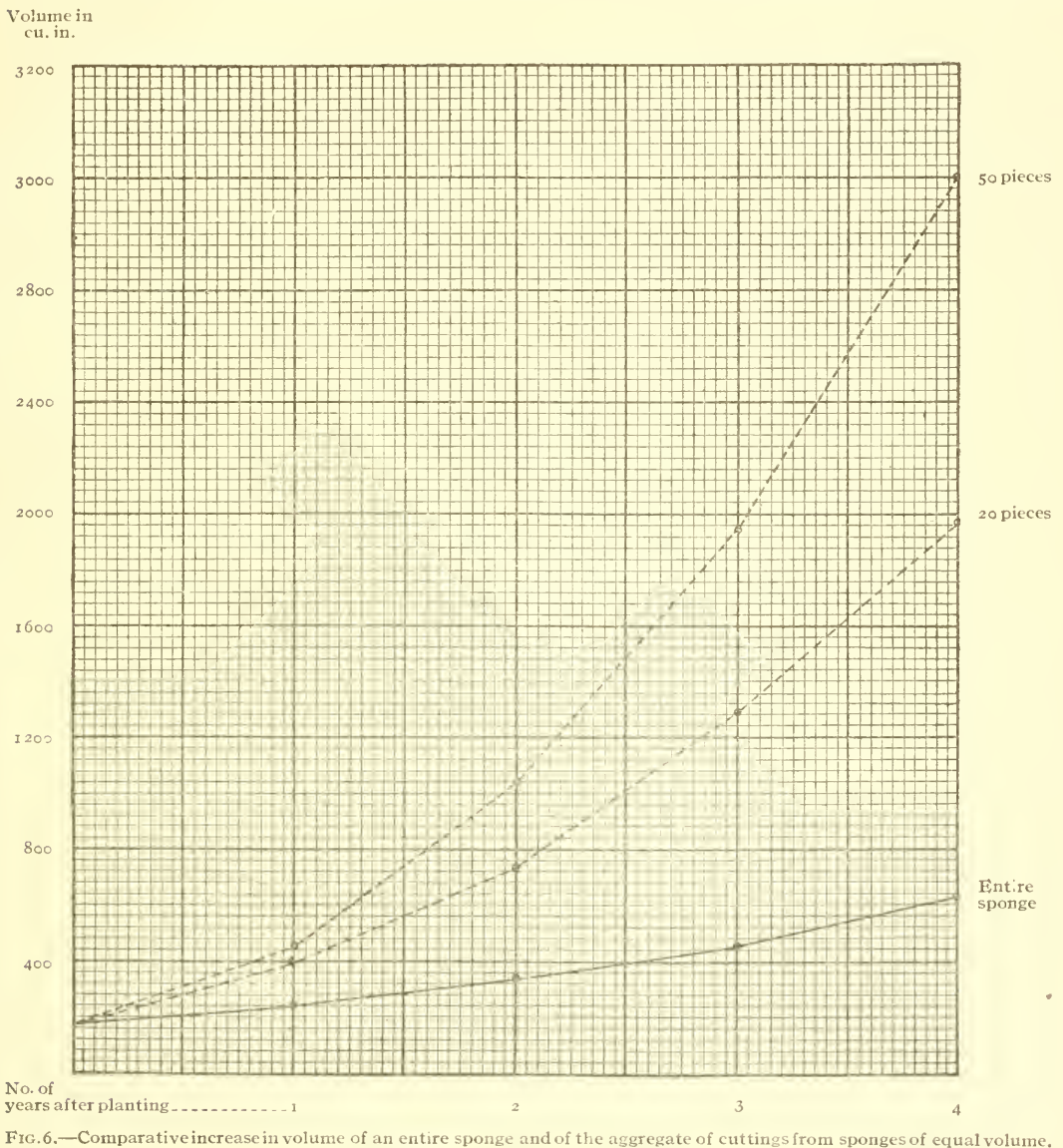

from a sponge of the same size will have a volume nearly 5 times as great. It should be explained, however, that these data do not represent a concrete case, but are based on observed rates of growth of cuttings and entire sponges under the same environment. The experiment begun to demonstrate these facts was interrupted by theft and vandalism. 
It should be stated also that 50 cuttings made from a 6 -inch sponge would be smaller than has been found advisable and the rate of increase in diameter during the first year would be somewhat smaller than has been assumed, though thereafter it would be fully equal to that of the larger cuttings.

\section{MORTALITY.}

The data upon the highly important question of the death rate among sponges grown from cuttings are not satisfactory. Buccich estimated it at about Io per cent in seven years, but my results indicate a somewhat higher rate.

Owing to the unsatisfactory character of the supports which were employed during the early years of the experiment, it was necessary to shift the sponges from time to time, each handling resulting in some loss, and moreover the breakage of the lines often allowed the plants to fall to the bottom, where they were much injured by adverse conditions. The mortality was highest at Anclote Key, where the plantation was exposed to the full force of the waves and the parting of the lines was frequent, and it was least at Sugar Loaf Key, where the greatest shelter was afforded. At Anclote there also was always more or less fall in the salinity during the heavy rainfall of summer, and the greatest mortality on the lines which remained intact was invarially coincident with this. Cuttings planted in the fall frequently reached the late spring months with a mortality of but I or 2 per cent, a rate increased to 8 or io per cent by fall. The observations made at that place are of value only as indicating the necessity for estallishing the plantations in places not subject to the influence of freshets in neighboring streams. At Cape Florida, in Biscayne Bay, the plantation was more sheltered from boisterous seas, but the surface water was liable to fall in salinity during summer with a coincident increase in the death rate, though here the results were not so uniform. At this place various lots of sponges planted at different times and all subject to more or less of the vicissitudes of experimental work mentioned above, exhibited mortalities of 32 per cent at the end of fifty-three months, 29 per cent at the end of forty months, and I 5 per cent at the end of twenty-six months, respectively. The first two lots were subject to damage from the breaking of the wires, but the last did not have this condition to contend with and the mortality during the last twenty-one months was equal to but 4 per cent of the original number planted. 'The heavy death rate of the first five months was due to the sagging of the wire so that the cuttings lay anong the dense vegetation, none of those raised above the top of the grass dying during that period.

At Sugar Loaf Sound no difficulty was experienced with fresh water, and the death rate was correspondingly decreased. The lot of 400 cuttings having the longest period of growth at that place-thirty-five months-exhibited at the end of that time a mortality of it per cent. All of these were transplanted at 
least once after having lain for an unknown time on the bottom vegetation under conditions which other experiments lave shown to be inimical, and a considerable proportion of the deaths occurred at those times. Had the wires remained intact and the cuttings been kept always suspended above the vegetation the death rate at the end of three jears would undoubtedly have been

Per
cent.

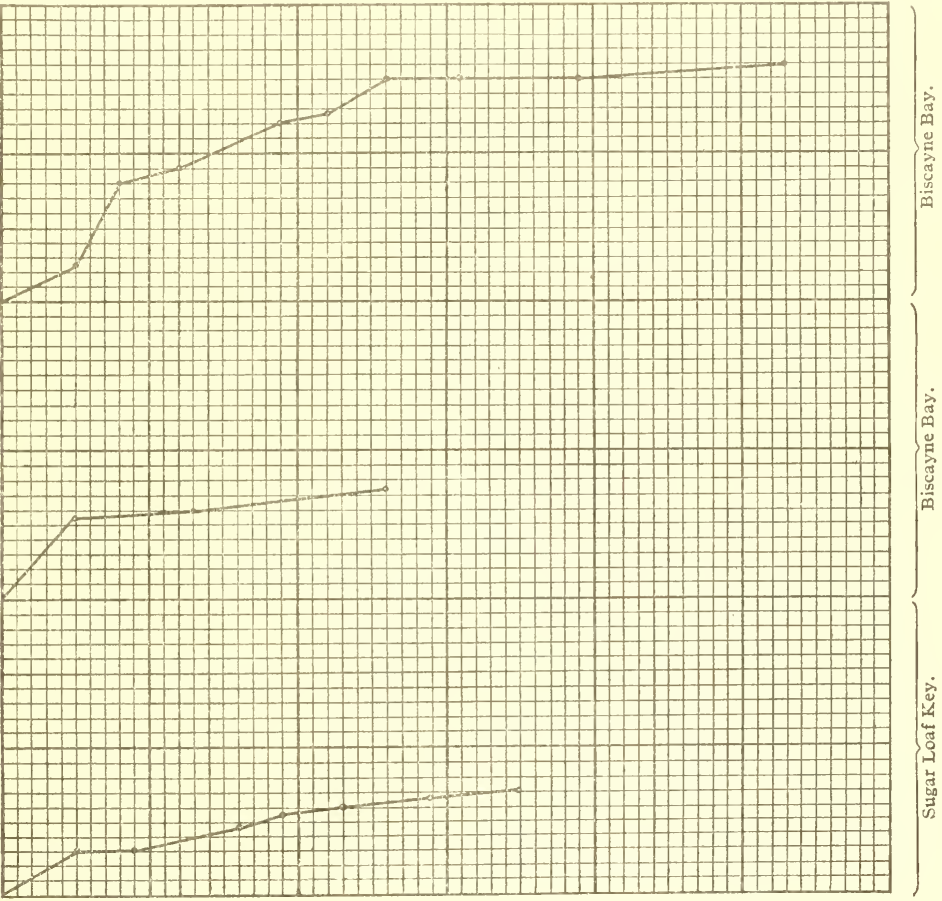

No. of

months after planting . - IO

20

30

40

50

60

FIg. 7.--Percentages of mortulity among different lots of sponges grown from cuttings at Sugar Loaf Key and Biseayne Bay.

under so per cent. Curves showing the percentage of mortality among different lots of sponges at Sugar Loaf Key and Biscayne Bay are shown in figure 7 . These sponges were all on wires suspended above the bottom.

At Anclote Key, owing to the almost constant turbidity of the water, it has been found impossible to determine the mortality among sponges planted on the bottom. At Cape Florida, in order to obtain data on this point and to 
avoid the error due to the liability to overlook disks from which the sponges may have become detached, practically all sponges planted on the bottom were attached to triangles either with or without spindles, each holding six cuttings. At that place the mortality at the end of six months was less than 3 per cent, and at the end of nineteen months a little less than 6 per cent, the latter including a few sponges in shoal water evidently detached by being fouled by the centerboard of a boat, and at thirty months 9 per cent. At Soldier Key, also in Biscayne Bay, the death rate among sponges planted on triangles on smooth rock bottom was about 3 per cent at the end of ten months. Data relating to bottom planting for longer periods are not available, the first extensive experiment in this direction having been destroyed by the great hurricane of 1906 .

From the results recounted it is believed safe to assume that in localities free from influx of fresh water and the extensive deposit of silt or sand, with sponges planted on disks or triangles on rocky bottom, or on other bottom free from vegetation and stable enough to prevent the gradual sinking of the attachments, the mortality will be well below 5 per cent per annum.

\section{SHAPE AND QUALITY.}

Under artificial culture the shapes of sponges may be modified more or less to suit the special requirements of the arts. Sponges grown on wires or spindles assume a spheroidal shape with a uniform texture of surface and devoid of any semblance of a "root," such as is found in all natural sponges excepting rollers. This form is very attractive and durable.

Cuttings grown on disks tend to assume a flatter shape and the surface attached to the cement is plane, in that respect resembling the root of natural sponges, but instead of being "raw" and exposing the canals it is covered with a close soft felt of great strength and durability, and forms the strongest instead of the weakest part of the sponge (pl. Lxxvi).

In certain arts and trades sponges with flat surfaces are required and to obtain these it is customary to cut the entire "forms" into pieces. The raw surfaces exposed in this way lack the durability of the natural surface and to obtain the latter, while at the same time retaining the several flat faces and sharp angles of the "cuts," a modified form of disk was employed. In this there were two partitions raised to a height of 4 inches, crossing one another at right angles on the upper surface of the disk. This left at the center of the disk four angular compartments, and in each of these a cutting was planted, which, being limited on three sides by the disk and two partitions, respectively, grew into a form having three plane surfaces at right angles to one another and one convex surface. The latter is similar in texture to the outside of an ordinary sponge, but the plane faces form contact with the disk and partitions and 
develop a smooth, soft, and very durable felt-like surface. These sponges cost more to grow than those of ordinary shape, but experiments recently inaugurated will probably make the additional cost of production trifling. The superior durability of sponges grown in this manner should make it possible to market them at a price considerably above that brought by the natural product.

It has been found that the sponges grown suspended above the bottom are superior in density and closeness of fiber to the natural sponges from the same locality. The same superiority is not apparent in those grown on disks, but the absence of the torn surface or root which characterizes the natural product makes them much more durable than the latter, the close felting of the attached surface making it the softest and strongest part of the sponge. In other words, the place of greatest weakness is converted into that of greatest strength, while the other parts remain normal. The artificially grown specimens are always superior to the natural product of the same immediate locality.

At Anclote Key a considerable proportion of the sponges grown on the bottom are affected with so-called crab holes, cavities which commonly contain small crabs. The general opinion of the spongers is that the crustaceans produce the holes, but of this I am by no means assured. As has been explained heretofore in this paper, practically all of the sponges planted on the bottom in this locality were previously injured by fresh water and already bore patches of dead tissue when planted on the bottom. As these dead areas sloughed away they left cavities, and I believe that these invited the crabs, which thus did not actually excavate their hiding places. In the many hundreds of these crab holes which I have examined in both artificially and naturally grown sponges I have never seen the slightest indication of a raw surface which looked as if the crab had torn away the tissues of the sponge. The presence of the crab, however, undoubtedly prevents the hole from filling up as it would tend to do under other conditions. In none of the healthy sponges planted on the bottom in Biscayne Bay do these holes occur, though they are found in the usual proportion in the natural sponges of the vicinity.

\section{HARVESTING.}

With the wire method of suspension from stakes, if such can be commercially developed, the problem of gathering the crop is simplified, for all that is necessary is to detach the wire at one end and slide the sponges off. As has been shown in the foregoing, however, this method has not yet been perfected and can hardly be commercially considered as yet.

With bottom planting on disks or spindles the method of harvesting will vary with the depth of water. In comparatively shallow water the crop can be taken up when matured by means of hooks, and the conditions essential are 
the same as for ordinary sponging-the weather must be moderate and the water clear. In deep water, beyond the reach of the hooks, it will be necessary to employ divers to gather the sponges, which will materially increase the capital required and the expense of operation. As has been explained previously, the operations of harvesting and replanting can be economically combined.

TRANSPORTATION AND ACCIIMATIZATION.

The transportation of seed sponges by water has been dealt with in another connection, but experiments indicate that they can also be carried considerable distances overland if proper precautions be observed. IVith the air temperature ranging between $7 \mathrm{O}^{\circ}$ and $80^{\circ}$, specimens have been easily kept without injury by merely packing them in wet seaweed in tubs. Others have been shipped by express, closely packed with wet eel grass and gulf weed (sargassum) in orange crates, over distances requiring three days between the time of removal from the water and the time of replanting. Although carried in heated express cars they were absolutely uninjured and started growth immediately after transplanting. Of another lot shipped on a six days' journey under the same conditions nearly all were killed.

If kept cool, the sponges will live much longer, and there is reason to believe that if carried in moist packing in refrigerator cars there would be little doubt of their surviving a trip extending over one week. Thus, witl proper arrangements Florida sponges could be carried alive to the California coast. With similar arrangements and with the facilities which would be afforded for giving the sponges occasional refreshing baths in sea water it is believed that little difficulty would be experienced in carrying specimens from the Mediterranean to Florida. The water used in moistening the sponges and the packing material must be of full oceanic salinity, an experiment having shown a mortality of 50 per cent among sponges sent on a three-day journey when a portion of the packing material was inadvertently moistened with nearly fresh water from Anclote River.

But while there may be little difficulty in transporting sponges to distant places and acelimating them in suitable waters, there is grave doubt if they will retain the characteristics which they exhibit in their original habitats. Sponges from the vicinity of Anclote Key transplanted to Biscayne Bay undoubtedly gradually developed some of the characters of indigenous specimens, but unfortunately the experiment to determine this point conclusively was seriously interfered with by a liurricane which intermingled the various lots. All of the transplanted specimens which could be definitely identified, about 15 in number, had completely lost their original characteristics at the end of two 
years, and it is probable that one not knowing their history would be unable to distinguish them from those grown from indigenous seed. The close-set bristles which cover the surface of wire-grown sponges at Anclote have been replaced by flat brushes of fiber, the oscula, formerly inconspicuous, have become larger and resident on the summits of short tubular processes, the general texture of the sponge is more open, and, finally, the fibers have become thoroughly charged with the characteristic red color of the Key sponges. In some specimens the red coloration is more pronounced than is normal in the locality to which the sponges have been transplanted.

At Anclote, also, it was observed that whatever the source of the seed there was a strong tendency of the plants to advert to a common type, though there appeared to be a tendency to. compromise between the influences of heredity and environment. Deep-water sponges a year after the cuttings were planted assumed the bristly appearance above referred to, but the processes were shorter and blunter than in sponges grown from shoal-water seed. The texture of the skeleton was also closer and more dense than in the cuttings of shoal-water origin, but neither resembled very closely the sponges from which they were derived. With these facts in view, it is almost certain that Florida sponges transplanted to the California coast, or Mediterranean specimens carried to the waters of Florida, will not retain their original characters, but it does not follow that they will be inferior. It is even possible that with judicious selection localities may be found where the transplanted products may prove superior to their fellows at lome, though it is true that one can hardly expect to improve on the quality of the fine sponges of the Mediterranean.

\section{ECONOMIC APPLICATION OF THE METHOD.}

ESSENTIAL CONSIDERATIONS.

The choice of a locality for conmercial sponge culture is a highly important consideration. In the first place, it must be one that can be guarded, for whatever the law may be it can not enforce itself, as has been amply demonstrated by the history of the oyster industry and some of my own experience in sponge culture. For this reason the small planter will have to select his location near shore, where he can live and himself guard his property, and this practically restricts the choice for such persons to the region of the keys. The large planter, employing a number of persons, can afford to station a guard boat on his plantation, and can therefore carry on his operations farther from slore and on the high seas.

Selection also must be made of a locality not subject to the effects of freshets and heary rainfall on the adjacent mainland, and for this reason the 
vicinity of the mouths of rivers must be avoided. The water should at all times be of a saltness not much below that of the open sea, and no locality where it frequently falls below a specific gravity of I.OI 9 or 1.020 , reduced to a standard temperature of $60^{\circ} \mathrm{F}$., can be regarded as safe. Disastrous experience on the plantations of the Bureau and of Messrs. Cheyney and Bigelow at Anclote Key, where the density, especially near the surface, fell below i.or 8 for a considerable period and killed the majority of the sponges, emphasizes this consideration. Along the keys below Lower Matecumbe or between the upper end of Key Largo and Cape Floricla this trouble is not likely to be experienced, but there are few places near the mainland opposite the keys or in the Gulf of Mexico, where localities close to shore can be occupied without apprehension from this cause. Several years may intervene between successive periods of fresh water, and the fact that it does not occur for one or two years does not guarantee that a plantation will not experience its effects just when the planter is beginning to hope to reap the results of his labor. With this consideration firmly in view, there is no great difficulty in avoiding most of the disasters which have affected the experimental work.

The experiments with wires and lines for the suspension of the cuttings above the bottoms having not reached favorable termination, the use of soft muddy or densely grassy bottom can not be recommended, and the sponge grower is, therefore, practically restricted in his choice to such bottom as is more or less capable of supporting a natural growth of sponges. Disks and triangles tend to sink on mud marl or shifting sand, or are overgrown when deposited among dense marine vegetation, in any of which contingencies the cuttings are either killed or injured. Even when the sponge is but partially buried in sand the basal portion will die from suffocation, and the still living upper parts will eventually lose attachment and be carried away. But a sparse growth of grass may prove highly beneficial in stimulating a more rapid growth of the sponges. This appears to be indicated by very recent experiments, and if it should prove true a large area of virgin bottom will be opened to productiveness. Otherwise, the selection of a sponge farm is practically limited to rocky bottom, though there are occasional localities where a mud bottom comparatively free from vegetation is sufficiently firm to support disks or triangles.

Care must be exercised also to avoid places where there is much sand carried in suspension in the water, as this will be deposited in eddies created by the sponges and their supports, and will gradually build up around the plants. This difficulty can be avoided on otherwise suitable bottom by raising the cuttings on spindles, so as to allow the currents to have a scouring action below the growing sponges. For attachments it is recommended that the disks described in a previous section of this paper be employed. The plain disk perforated by two holes is the simplest and cheapest form of attachment, but its 
use involves more labor than when the form with a short lead wire spindle is used. The cuttings should be bound to the disk by short pieces of no. I4 or no. I6 Brown \& Sharp gauge aluminum wire, passed through the substance of the cutting, and thence through the holes in the disk, the ends twisted together below.

The cuttings should be made as already described, and should have preferably a volume of 8 to ro cubic inches, measuring, say, $1 \frac{1}{2}$ by $2 \frac{1}{2}$ by 3 , or a little less. They should be made as regular as is convenient without the expenditure of additional labor. They can be handled and exposed to the air without special precautions, but should not be allowed to remain in foul water.

If the disks with short spindles are used, the cuttings may be merely threaded on to the spindle by means of a needle, as has been already described, the cuttings being pushed down into contact with the cement disk, to which, as well as to the spindle, they soon grow fast. The process is much more rapid and less laborious than wiring the cuttings to the plain disks, which fact almost compensates for the increased cost of material.

The triangles are not recommended excepting when it is necessary to use long spindles to raise the sponges above possible sand deposit, in which event they are less liable than the disks to capsize under the impact of the waves against the larger sponges. They are more difficult to handle and transport than are the disks, and more easily broken. When fitted with 8 -inch spindles of lead-covered iron ribbon, they cost about twice as much per sponge as do the disks, and the greater labor of transporting to any considerable distance will add to the difference in cost.

In shoal water the disks or triangles with the cuttings attached may be dropped overboard right side up. They will in the great majority of cases sink to an upright position on the bottom, though occasionally, in strong currents, one will capsize in its descent. Advantage should be taken of the first opportunity to inspect the planting, to right the capsized disks, and to shift any that may have fallen on those already planted. In deep water there is greater liability that the disks will capsize; the danger is less with triangles. Though the experiment has not been tried, it is probable that an inclined chute, one end resting on the bottom and the other coming to the side of the boat, down which the disks could slide, would not only insure an upright position of the disks, but would generally facilitate planting. As the boat was hauled ahead the disks would be distributed over the bottom in rows.

FINANCIAL ASPEC'TS.

The cost of planting will vary somewhat with the locality, but the following figures, based on actual experience at Anclote Key, are fairly representative of what may be regarded as average conditions. The computation is based on 
the requirements for planting I acre with a sponge on each square yard of bottom.

For plain disks:

$4,8,40$ clisks, at 2 cents

4,8 fo cultings, at 2 cents

$\$ 96.80$

Ialoor, planting, fiftecn datys, at $\$ 2$

For disks with slurt learl spindles:

The first cost is slightly in favor of the plain disks, the expense for aluminum bincling wire being so small as to be negligible, but when it is remembered that both kinds of disks are available for subseguent plantings when recovered, this advantage disappears. Assinuing that during four years of growth 20 per cent of the original cuttings die and that the disks to which they were attached are lost on account of their inconspicuousness, each of the above accounts would have to be eredited with the value of the disks recovered, so per cent, amounting to $\$ 77.41$ in the first case and $\$ 96.80$ in the second, making the actual cost of planting in the two cases \$1.f6.16 and \$13.3, respectively.

In subsecpnent use of the disks for replanting, especially in leep water where a diver is employed, the advantage is strongly in faver of the disks with spindles for reasons that have been alreaty explained. The eost of harvesting the sponges ean not be stated, as there are no adequate data available. In shoal water, where the sponges conkt be taken by hooks and the replanting with fresh enttings $b$ carried on simultaneously, the cost would be slight. Whate a diver would have to be employed the expense would be leavier, but by using the spindles this eonld also be reclueed by planting fresh cuttings as fast as the nuture sponges are taken, withont removing the disks from the botton11. In most locilities in deep water there woukl also be a compensatory greater return on aceount of the superior quality of the sponges.

Assmming that there is no (xpense in gratarling the beds, but that this service is incidentally performed hy the men making the disks and planting the sponges, the apparent profits to le derived from sponge planting are as follows:

Net cost of platuling 1 atere with 4,8 fo cultings _

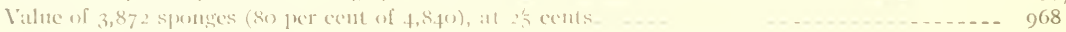

'lins, at the end of forn years from the date of planting, the net value of the sponges on the bottom wonkd be $\$ 8.35$, assuming that they hat grown at the rate demonstrated at Anclote Key and had attained an average weight of $I^{1}+$ onnces, lry, that the mortality (luring their growth was 20 pereent, and that 
the value of pure sponges is $\$ 4$ per pound, which is less than the average of recent years. 'lhese assumptions are all regarded as very conservative.

From this must be deducted the cost of harvesting, which, in shallow water such as is to be fotnd anong the keys, should not exeecl about $\$ 2.5$ if proper conditions of weather and water be availed of. 'llie net return, therefore, from an original investment of about $\$ 225$ per acre would be an average of about $\$ 200$ per year. In deeper water the cost of harvesting the crop would be somewhat greater, but as the operations would be carried on on a larger scale economies could be practiced which would reduce the expense.

In conclusion it should be plainly stated that the above calculation, thongh based on the actual results of experiment, is largely theoretical and that definite data can not be attained until the work is actually undertaken on a commercial scale. It is confidently helieverl, however, that if directions are followed in a suitable locality the actual net returns per acre will be consiclerably greater than those stated. 



\section{Plate LXIX}

Fig. 1.-Sheepswool cutting of about the size recommended for planting.

Fig. 2.-Sheepswool sponge 11 months old, grown on wire at Anclote Key from a cutting about one-half size of figure 1 . Natural size. 

Plate LXX

Fig. 1.-Sheepswool sponge 20 months old, grown on wire at Anclote Key from a cutting about one-half the volume shown in figure 1, plate Ixix.

Fig. 2.-Yellow sponge 21 months old, grown on wire at Sugar Loaf Key from a cutting about the size shown in figure 1, plate lxix. Natural size. 


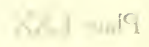

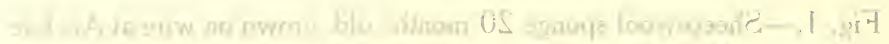

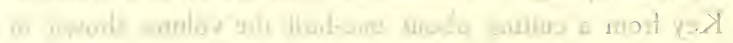

$$
\text { xisl otely. I mocht }
$$

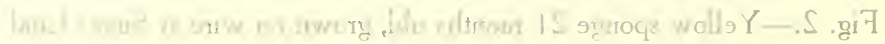

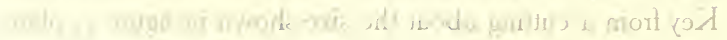

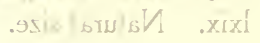




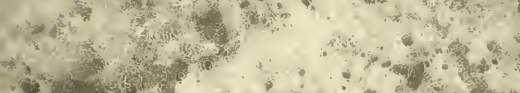

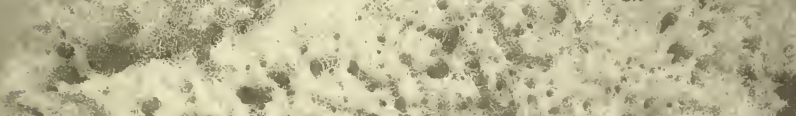

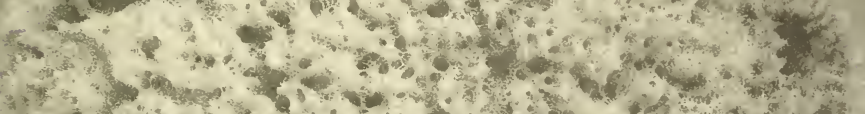

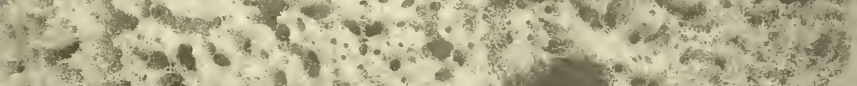

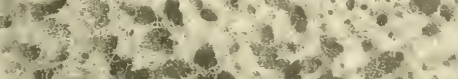

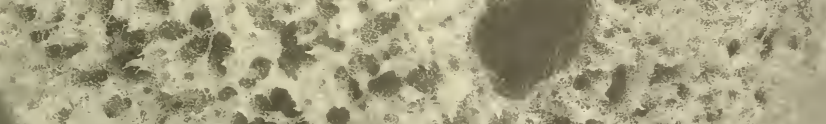

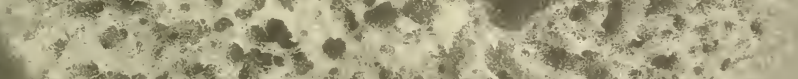

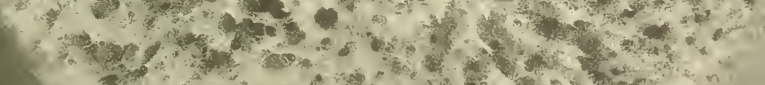

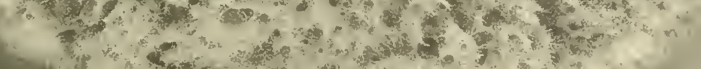

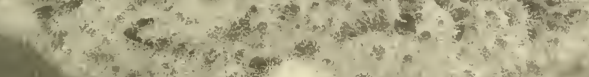
(x) 



\section{Plate LXXI}

Sheepswool sponge 31 months old, grown on wire at Anclote Key from a cutting about one-half the volume shown in figure 1, plate lxix. Nine-tenths natural size. 
IXX.I 91519

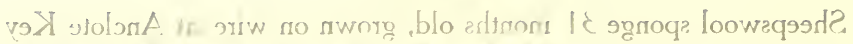

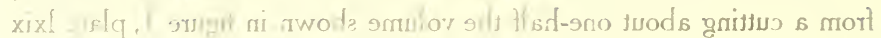

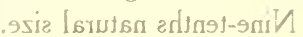




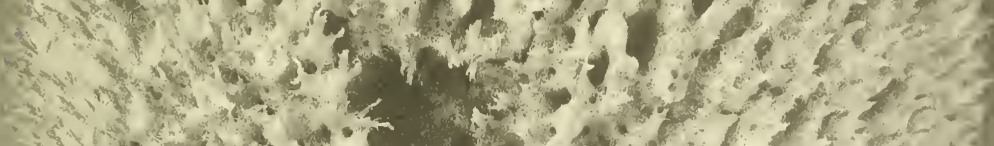

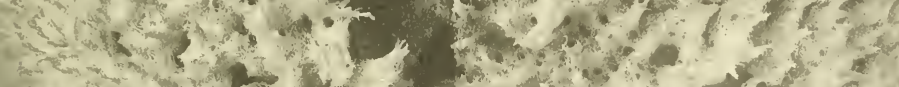

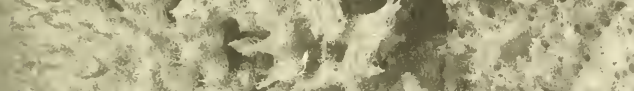

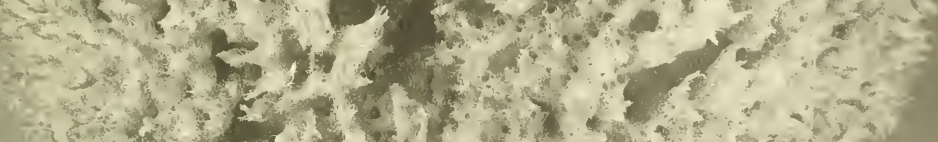

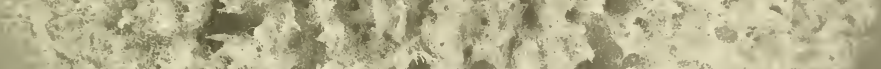

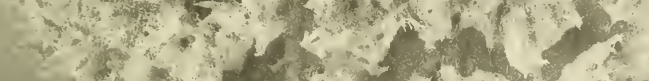

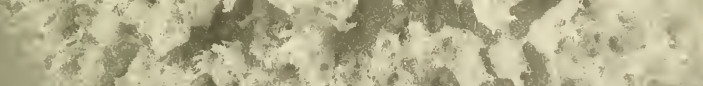

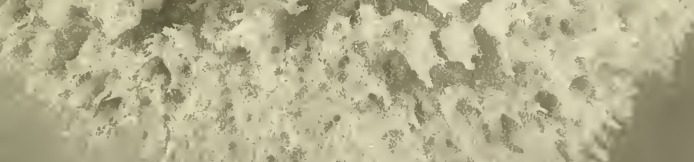

$$
\text { Wh t as is }
$$





\section{Plate LXXII}

Sheepswool sponge 35 months old, grown on wire at Sugar Loaf Key from a cutting about the size shown in figure 1, plate lxix. Nine-tenths natural size. 
IIXXI sive

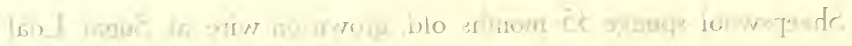

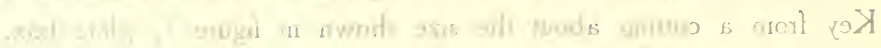

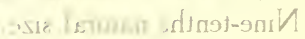




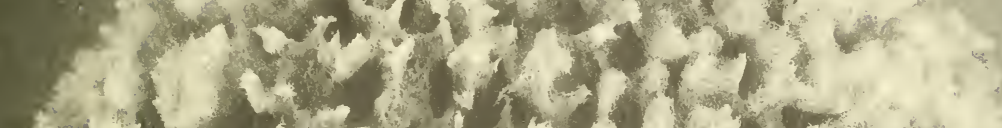

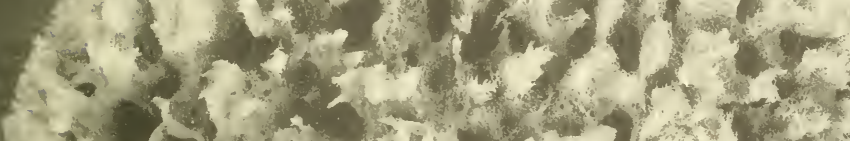

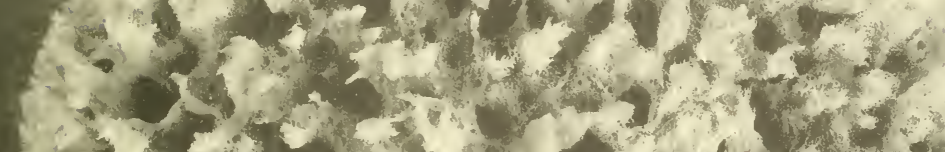

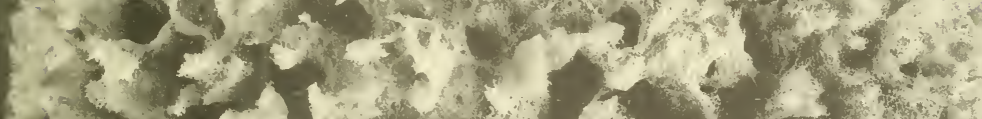

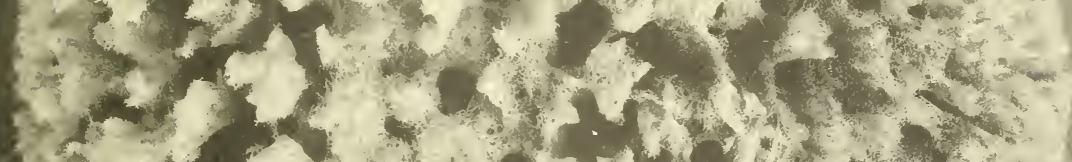

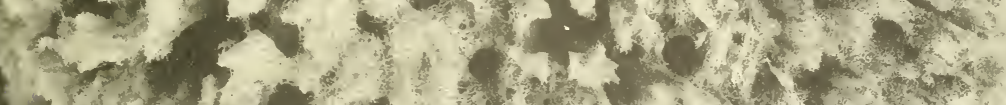

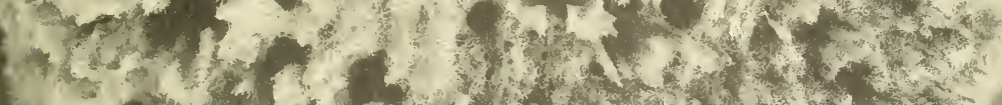

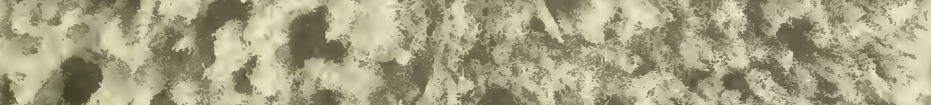

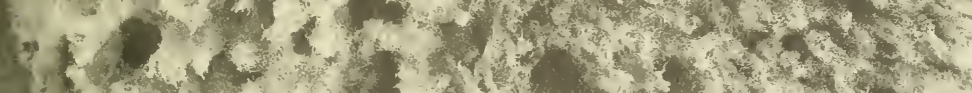

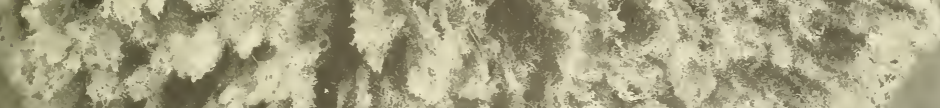

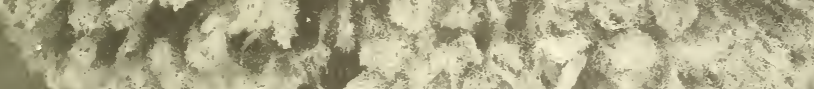

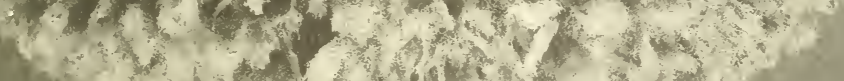

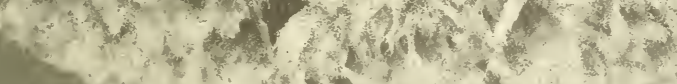

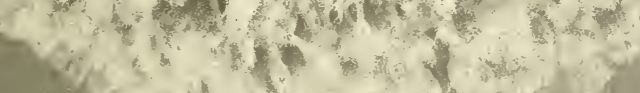

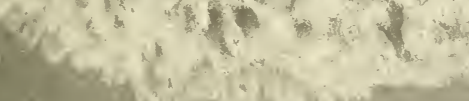





\section{Plate LXXIII}

Sheepswool sponge 52 months old, grown on wire at Cape Florida from a cutting about one-half the volume shown in figure 1, plate lxix. Weight, dry and thoroughly cleaned, $11 / 3$ ounces. Nine-tenths natural size. 


\section{III.YI I - IT}

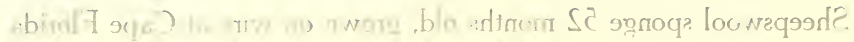

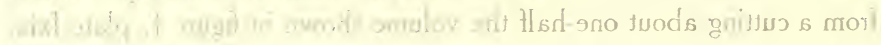

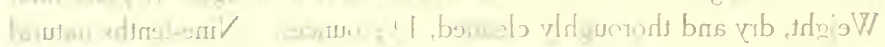




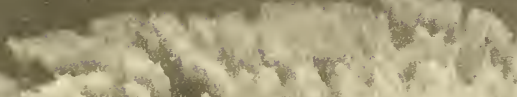

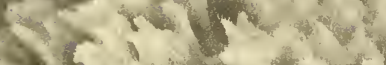

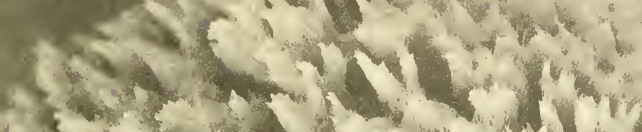

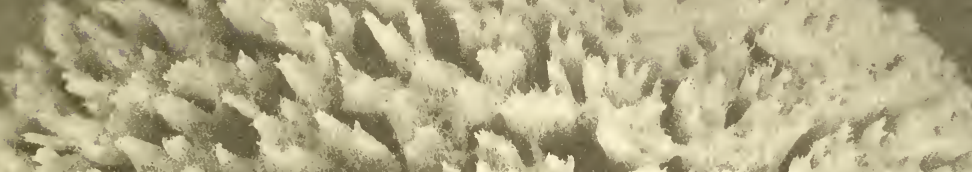

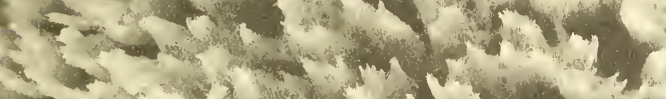

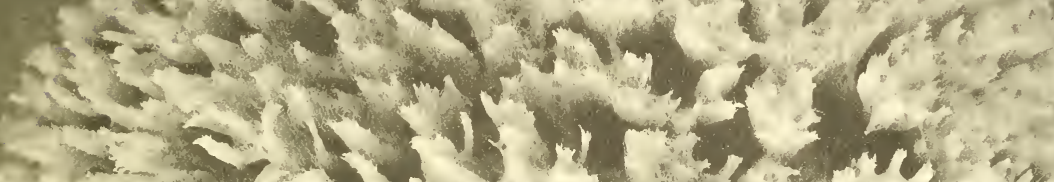

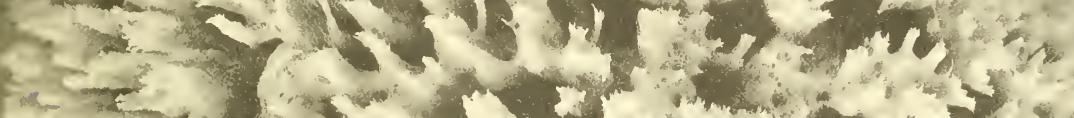

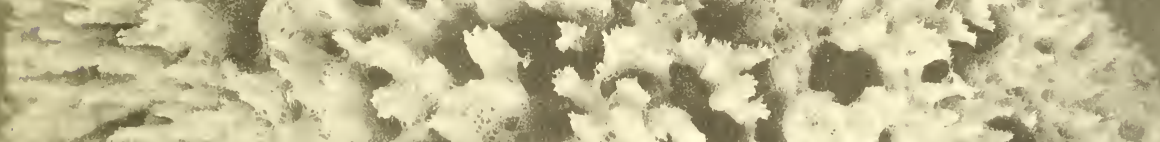

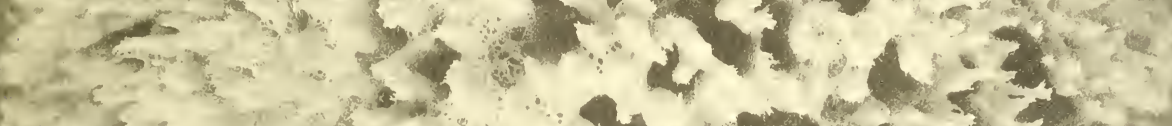

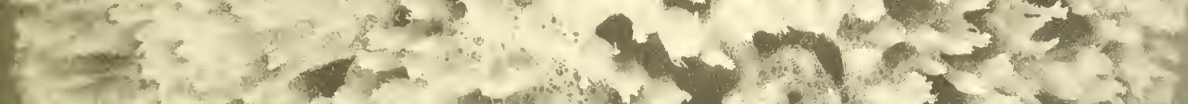

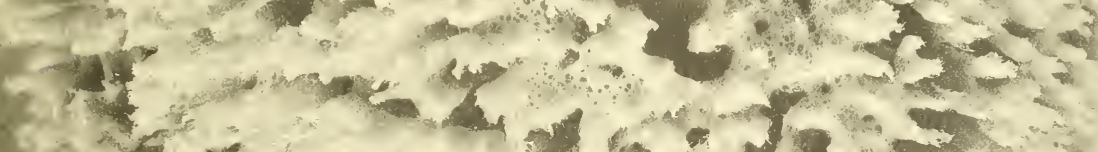

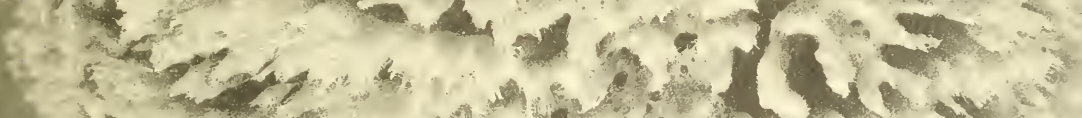

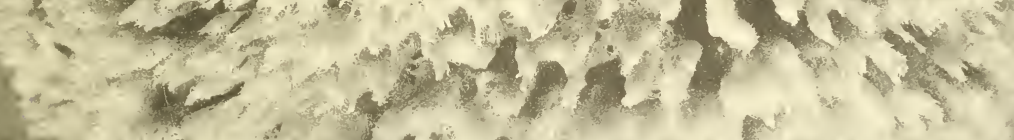

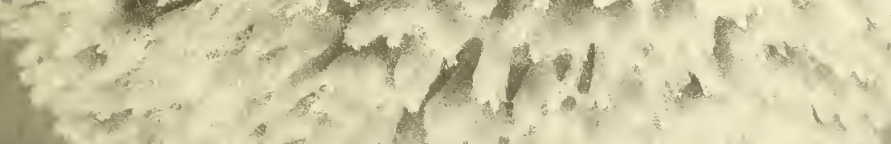





\section{Plate LXXIV}

Sheepswool sponge 35 months old, grown on spindles (plate lxvii) in Cape Florida Channel from a cutting about the size shown in figure 1, plate lxix. Weight, dry and thoroughly cleaned, 1 x/3 ounces. Nine-tenths natural size. 


\section{IIY I I 956 19}

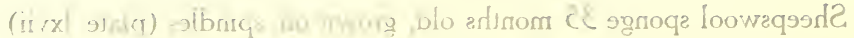

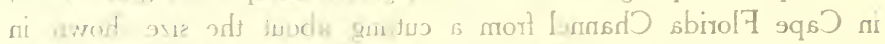

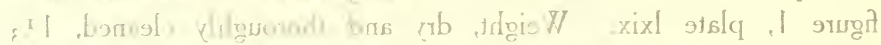

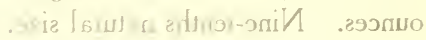




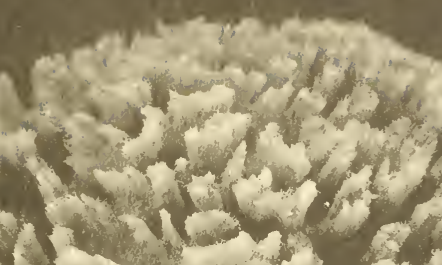

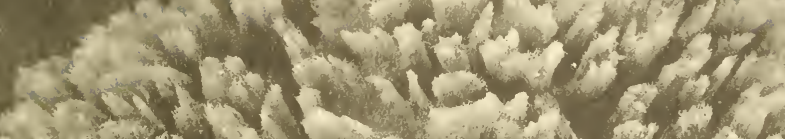
(5) (1)

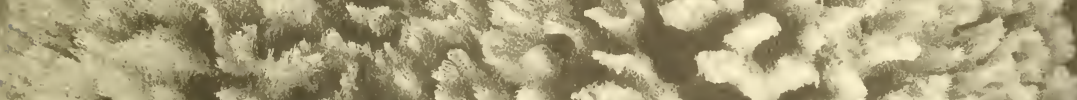

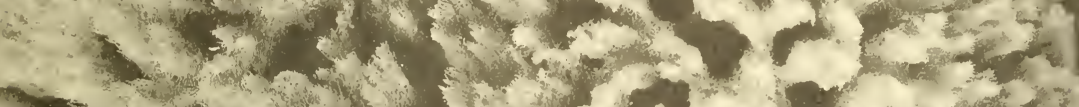

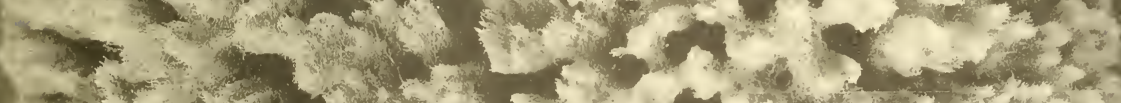

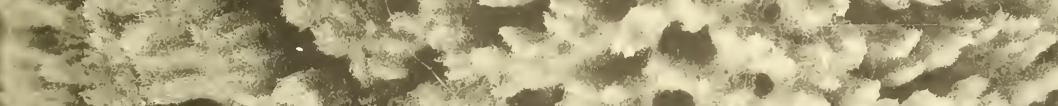

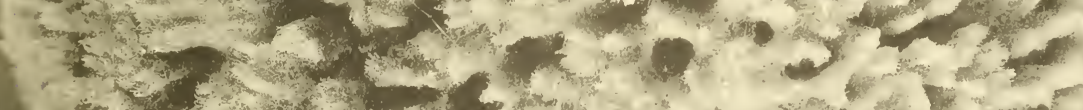

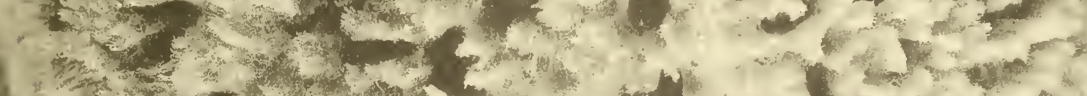

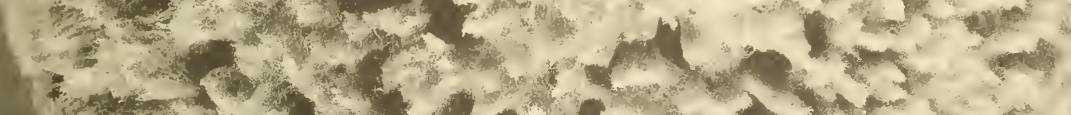

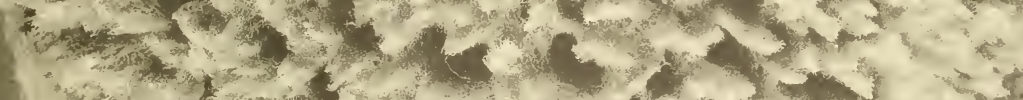

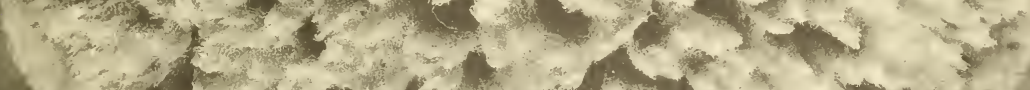

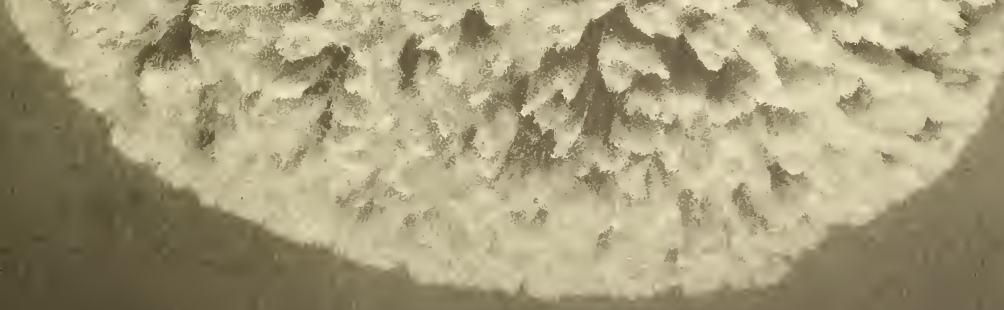





\section{Plate LXXVI}

Sheepswool sponge not over 48 months old, grown on a cement disk at Anclote Key from a cutting about the size shown in figure 1, plate lxix. Weight, dry and thoroughly cleaned, $11 / 2$ ounces. Ninetenths natural size. This illustration shows the closely felted soft surface in contact with the disk. The corresponding surface of a natural sponge is open, like the interior, and therefore weaker and less durable. 


\section{IJXXI 915 19}

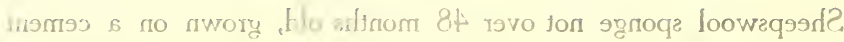

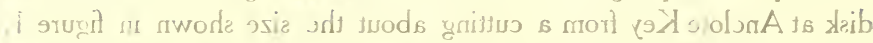

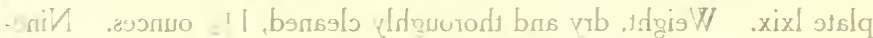

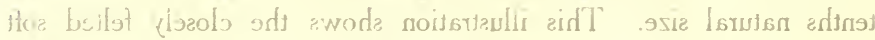

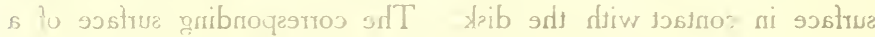

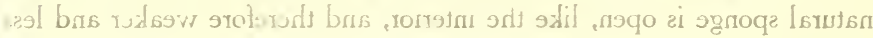




\section{It}

Nos:

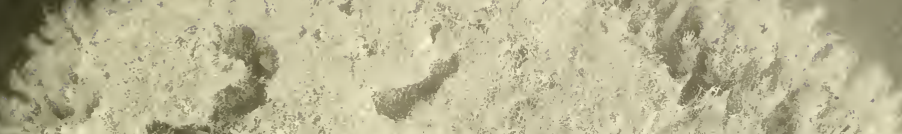

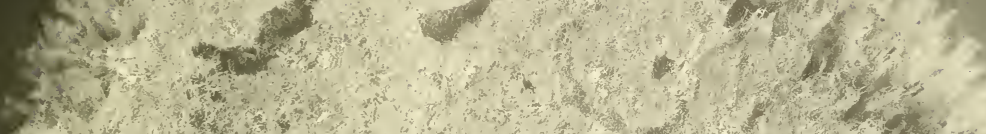

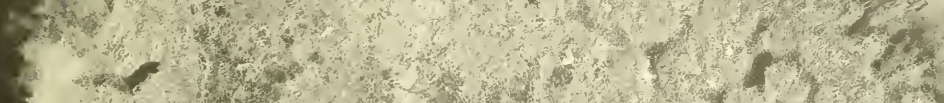

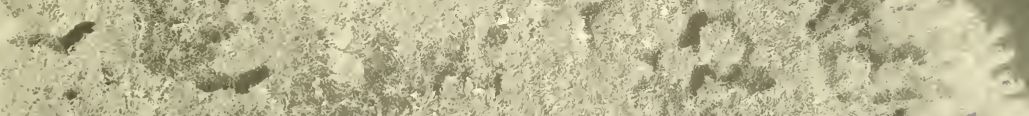

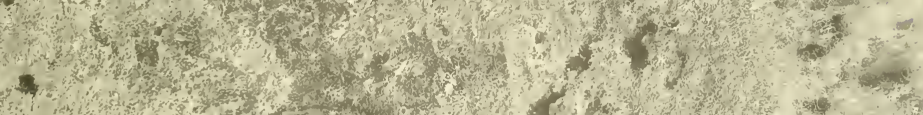

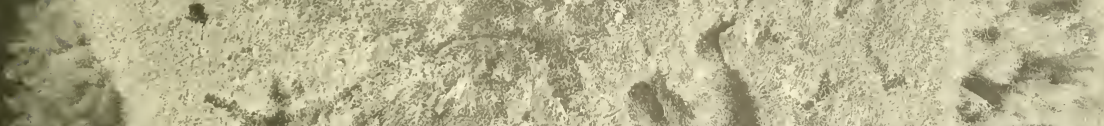

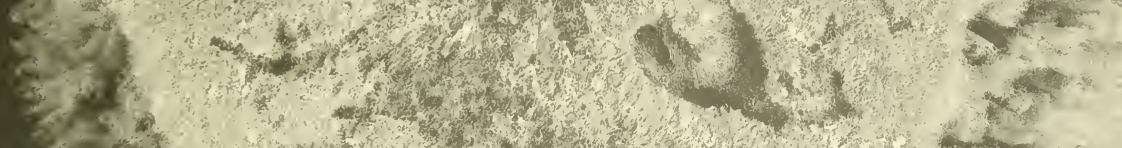

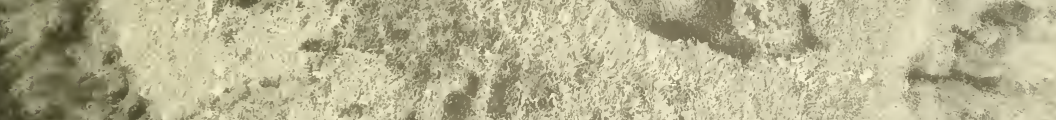

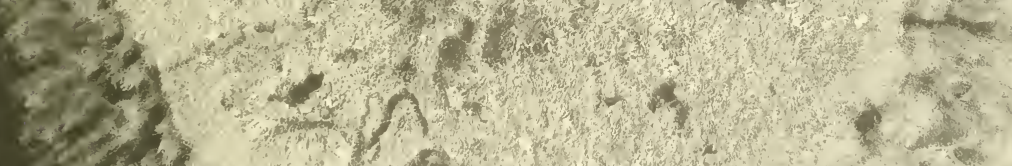

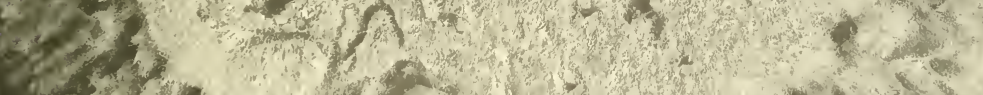

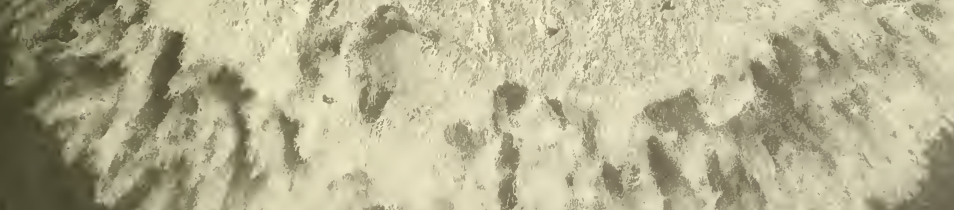

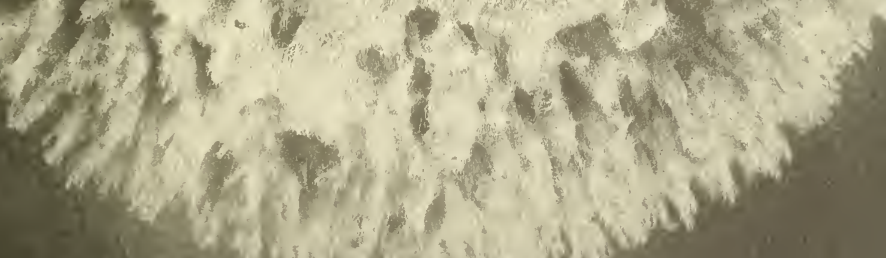










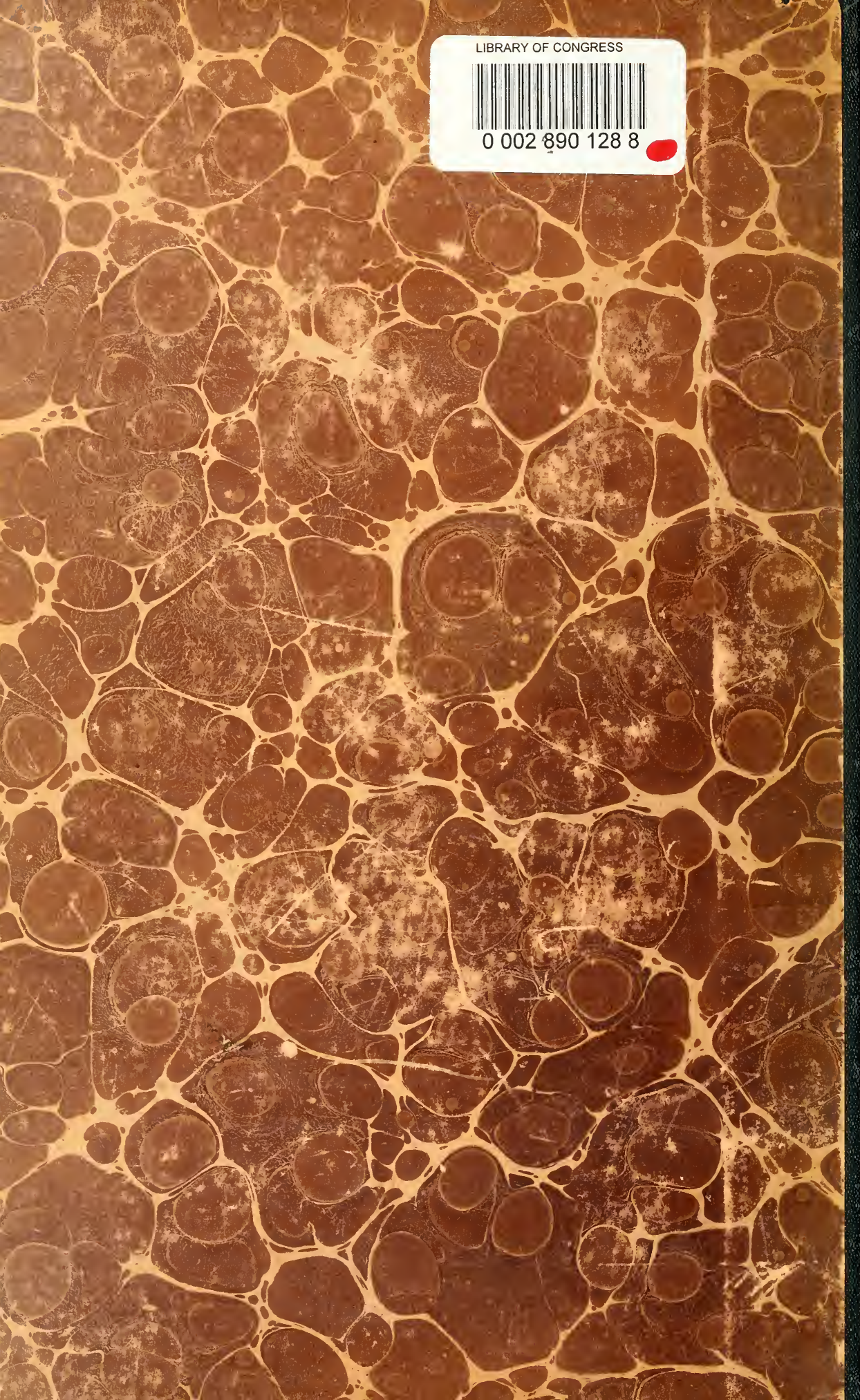

